\title{
Nuclear Medicine in the First Year of Life
}

\author{
S. Ted Treves, Amanda Baker, Frederic H. Fahey, Xinhua Cao, Royal T. Davis, Laura A. Drubach, \\ Frederick D. Grant, and Katherine Zukotynski \\ Division of Nuclear Medicine and Molecular Imaging, Children's Hospital Boston and Harvard Medical School, \\ Boston, Massachusetts
}

\begin{abstract}
Learning Objectives: On successful completion of this activity, participants should be able to describe, for children less than 1 y old, (1) the wide variety of nuclear medicine indications; (2) the nuclear medicine studies, relative to other imaging methods, that can provide the highest diagnostic yield; (3) how to obtain high-quality nuclear medicine examinations at the lowest radiation exposures; (4) how growth and development affect the appearance, and therefore the interpretation, of nuclear medicine images; and (5) special care needed, such as patient preparation, immobilization, distraction techniques, environment, sedation or general anesthesia, imaging techniques, image processing, and presentation of results.
\end{abstract}

Financial Disclosure: The authors of this article have indicated no relevant relationships that could be perceived as a real or apparent conflict of interest.

CME Credit: SNM is accredited by the Accreditation Council for Continuing Medical Education (ACCME) to sponsor continuing education for physicians. SNM designates each JNM continuing education article for a maximum of 1.0 AMA PRA Category 1 Credit. Physicians should claim only credit commensurate with the extent of their participation in the activity.

For CE credit, participants can access this activity through the SNM Web site (http://www.snm.org/ce_online) through June 2012.

Nuclear medicine has an important role in the care of newborns and children less than $1 \mathrm{y}$ old. Patients in this age group present with a spectrum of diseases different from those of older children or adults. These patients can benefit from the full range of nuclear medicine studies. In these young children, nuclear medicine studies are more likely to be used to evaluate a wide range of congenital conditions but also can be helpful for evaluating acquired conditions such as infection, cancer, and trauma. This review first will cover the general aspects of nuclear medicine practice with these patients, including the special considerations that can help achieve successful diagnostic imaging. These topics will include clinical indications, imaging technology, instrumentation, software, positioning and immobilization, sedation, local and general anesthesia, radiopharmaceutical doses, radiation risk, and dose reduction. The review then will discuss the specific nuclear medicine studies that typically are obtained in patients in this age group. With extra care and attention to the special needs of this population, nuclear medicine departments can successfully study patients less than 1 y old.

Key Words: pediatrics; clinical applications; infants, nuclear medicine

J Nucl Med 2011; 52:905-925

DOI: 10.2967/jnumed.110.084202

$\mathbf{N}$ uclear medicine plays a valuable role in the evaluation of pediatric patients in the first year of life. Evaluation of these patients differs from that of other children and must

Received Mar. 16, 2010; revision accepted Apr. 5, 2011.

For correspondence or reprints contact: S. Ted Treves, Division of Nuclear Medicine and Molecular Imaging, Children's Hospital Boston, Joint Program in Nuclear Medicine, Harvard Medical School, 300 Longwood Ave., Boston, MA 02115.

E-mail: treves@childrens.harvard.edu

COPYRIGHT @ 2011 by the Society of Nuclear Medicine, Inc. accommodate a different range of clinical problems, special imaging requirements, and extra care to acquire high-quality images that address the clinical question while delivering the lowest radiation dose possible. This review therefore will address special aspects associated with the imaging of these small children, including clinical indications, methods, patient handling, positioning, immobilization, sedation, administered radiopharmaceutical dosages, instrumentation, evaluation of radiation exposures and risk, and reduction of radiation exposure (1).

Clinical indications are broad and include the diagnosis and assessment of diseases of the central nervous, endocrine, cardiopulmonary, lymphatic, gastrointestinal, genitourinary, and musculoskeletal systems, as well as oncologic diseases. This is based on a retrospective review derived from the experience at our institution from 2000 to 2009. During this period, approximately 2,570 children under $1 \mathrm{y}$ old underwent one or more diagnostic procedures, for a total of 3,330 studies. There were slightly more boys (maleto-female ratio, 1.14). Patient ages ranged from premature infants to 12 mo. Two thirds of the studies were of patients less than 6 mo old.

\section{TECHNICAL CONSIDERATIONS}

\section{Imaging}

Imaging of neonates and infants requires special care, patience, adaptation, experience, and skillful hands. Individual approaches are often needed that require deviation from routine protocols with respect to the administered radiopharmaceutical doses, imaging techniques, and types of images needed.

During the first year of life, infants naturally experience rapid growth and development, and radiopharmaceutical distribution and kinetics may vary from that in older children or young adults. For example, newborns and infants have a 
lower glomerular filtration rate, faster circulation, and faster pulmonary wash-in and washout of radioactive gases than older children. The uptake of pertechnetate in the gastric mucosa is lower and the background higher in infants than in older children. The distribution of skeletal imaging agents in this group of patients reveals relatively high tracer concentrations in growth centers and a lack of tracer uptake in the nonossified cartilaginous parts of the growing bone (Fig. 1). As a child matures, physiologic processes mature, and the kinetics and biodistribution of radiopharmaceuticals eventually reach adult levels.

Imaging of these patients must take into account the challenges of evaluating small organs and bodies with equipment designed for imaging adults. Newborns weigh an average of $3.4 \mathrm{~kg}$ (range, $2.5-4.5 \mathrm{~kg}$ ). By $1 \mathrm{y}$ old, the baby has tripled its birth weight to approximately $10 \mathrm{~kg}$ (range, $7.5-12 \mathrm{~kg}$ ). Premature babies ( $<37$ wk of gestation) usually weigh less than $2.5 \mathrm{~kg}$, but some weigh as little as $800 \mathrm{~g}$ or even less.

\section{Positioning, Immobilization, Sedation, and Local and General Anesthesia}

Most nuclear medicine imaging requires the patient to remain still for a relatively long period. In babies, simple immobilization techniques (sandbags, safety belts, gently

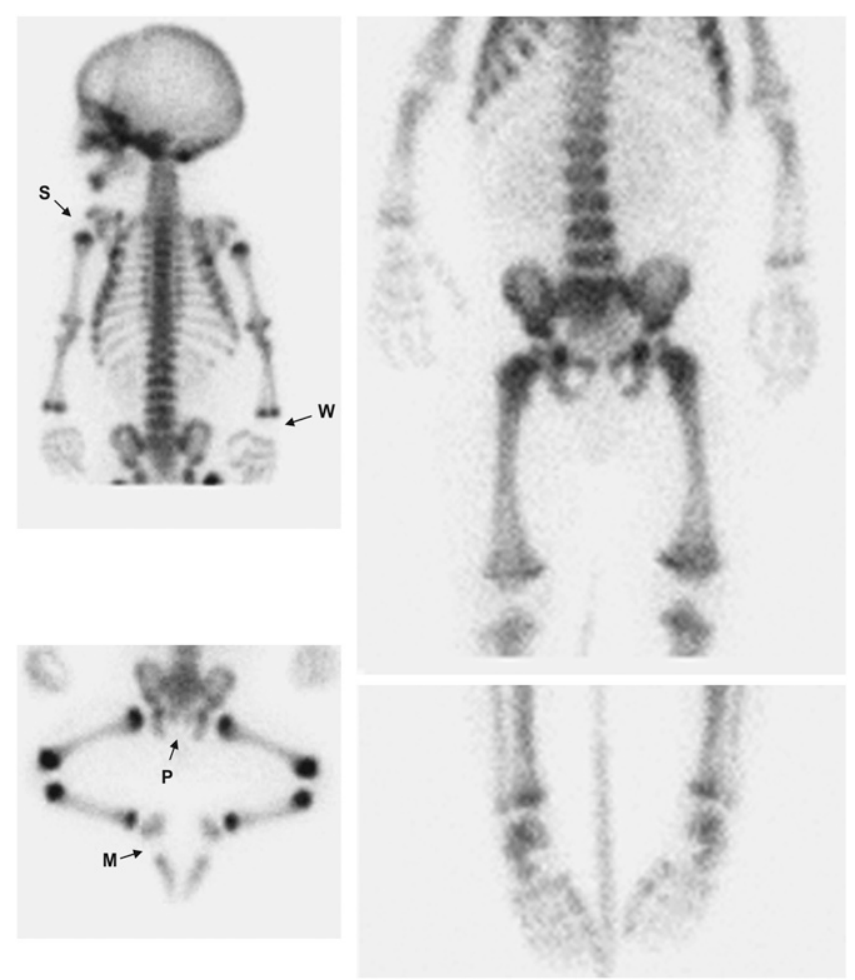

FIGURE 1. Nonossified bone. ${ }^{99 m}$ Tc-MDP skeletal scans. (Left) In 1-mo-old baby, there is no tracer uptake in humeral heads (S), femoral heads, femoral necks, distal femur, proximal tibia, pubic bones $(\mathrm{P})$, or bones in midfoot (M). (Right) In another patient at 11 mo old, tracer uptake in femoral head and neck, bones of knee, and midfoot shows evidence of calcification. Bones of elbow, wrist bones, and pubic bones are still not completely calcified. wrapping a bed sheet around the patient) and some holding by the gentle and skilled hands of nuclear medicine technologists help to ensure success. Newborns usually find swaddling comforting. In a quiet environment, with dim lights and care, many of these children fall asleep during longer examinations. Attenuation imaging artifacts resulting from holding patients by hand should be avoided if possible, but they should be anticipated and recognized on images. Allowing the child to hold a favorite toy or stuffed animal during some examinations may be permitted as long as it does not interfere with imaging. Our imaging rooms are equipped with television monitors that can be positioned within easy view by the patient. Video or audio programs often help to distract and relax patients (and parents) during the examination. Even if the patient moves during an examination, motion correction techniques can be applied effectively to aid in the qualitative and quantitative evaluation of images (2). Local skin anesthesia with cream containing lidocaine and prilocaine (e.g., EMLA cream; AstraZeneca LP) is helpful in reducing pain associated with venipuncture.

Infrequently, immobilization alone is not sufficient, and sedation or, much less frequently, general anesthesia is necessary. In our review, less than $3 \%$ of the children in this age group needed sedation, mainly for brain or whole-body SPECT or PET. Under optimal conditions, institutions have specialized pediatric sedation programs with dedicated teams of anesthesiologists and nurses who have particular experience with patients needing imaging. When sedatives are administered, potential side effects such as aspiration and respiratory arrest should be anticipated and appropriate means of treatment must be available. A physician or nurse must monitor the child from the time of sedation until full recovery. To support sedation, the nuclear medicine department must be equipped with age-appropriate medications and equipment. Sphygmomanometers and stethoscopes appropriate for these children should be within easy reach. Sedation or general anesthesia can affect physiology, such as cerebrospinal fluid flow, cardiovascular shunt flow, cardiac function, renal function, and cerebral function.

\section{Instrumentation and Software}

Optimal imaging of the newborn or infant requires special consideration of the appropriate choice of instrumentation, image acquisition technique, and processing technique. For planar imaging and SPECT in these small patients, choosing an appropriate imaging device is important and will depend on the particular study and the specific diagnostic task. A state-of-the-art dual-detector $\gamma$-camera system can acquire high-quality images of an infant. These cameras typically have a useful field of view of $50 \times 30 \mathrm{~cm}$. Both anterior and posterior images of the whole body can be obtained simultaneously in a reasonable period, thus reducing immobilization time. A fixed-geometry second detector may be in the way if the application requires direct access to the patient during imaging, and a dual-detector 
device that allows the second detector to be moved separately would therefore be preferable.

Choosing the appropriate collimator can make the difference between an excellent and a suboptimal study. The small size of the organs being imaged in the newborn or infant makes this choice even more critical. For some tasks, the ability to resolve a particular feature may be most important, and therefore an ultra-high-resolution collimator or pinhole collimator may be most appropriate even if requiring a slightly longer imaging time. In other instances, it may be necessary to acquire a less noisy image in a fixed amount of time based on the physiologic process to be evaluated, and therefore, a higher-sensitivity collimator may be a good choice. The ability to select from a variety of collimators (ultra-high-resolution, high-resolution, and high-sensitivity) provides flexibility to adapt to specific diagnostic needs. Pediatric nuclear medicine clinics also should have a high- or medium-energy collimator available for imaging ${ }^{123} \mathrm{I}$ agents such as metaiodobenzylguanidine (MIBG). Although the primary $\gamma$-ray emitted by ${ }^{123} \mathrm{I}$ has an energy of $159 \mathrm{keV}$, it also emits several higherenergy photons in low abundance ( $\gamma$-rays with energies higher than $400 \mathrm{keV}$ are emitted $2.6 \%$ of the time). Lowenergy collimators are not effective at stopping these high-energy photons, leading to a significant amount of septal penetration and image degradation. When a lowenergy collimator is used to image ${ }^{123} \mathrm{I}$, almost half the events measured within the $159-\mathrm{keV}$ window result from these high-energy photons. Using a medium-energy collimator produces images of superior quality, compared with the high-sensitivity or even ultra-high-resolution collimators (3).

In some cases, even an ultra-high-resolution collimator may not resolve small features of importance. Pinhole collimator magnification scintigraphy provides the highest spatial resolution (a few millimeters) with $\gamma$-cameras and, in selected applications, is invaluable for imaging small body parts. Pinhole collimator magnification spreads the image over a larger area of the detector, effectively improving the overall system spatial resolution above what can be achieved with parallel-hole collimators (4). Pinhole images using an insert of a small aperture $(2-3 \mathrm{~mm})$ in infants undergoing ${ }^{99} \mathrm{~m}$ Tc-dimercaptosuccinic acid (DMSA) renal scans or ${ }^{99 \mathrm{~m} T c-m e t h y l e n e}$ diphosphonate (MDP) bone scans are of excellent quality in the smallest patients (Fig. 2). The pinhole collimator has the lowest sensitivity of any of the collimators routinely used, particularly with the smaller apertures, and images can take several minutes (10-15 min) to acquire. For rapid dynamic studies, a low-energy converging collimator provides a good combination of higher spatial resolution and sensitivity.

In newborns and infants, SPECT recording can be particularly challenging because of the limited spatial resolution due to the relatively large distance from the patient to the detector. In most devices, SPECT detectors cannot get close to the patient, because the imaging beds are typically around $38 \mathrm{~cm}$ wide. Specially designed narrow pediatric pallets allow the detectors to come closer to the patient's body, improving SPECT quality. The use of focusing collimators and new SPECT gantries with advanced robotics has made such approaches much simpler for routine use in cardiac imaging and, therefore, may optimize SPECT for imaging neonates and infants.

Image fusion of complementary anatomic and functional 3-dimensional (3D) image sets is increasingly regarded as a necessary part of imaging. Image fusion registers 2 or more 3D image sets of the same or different imaging techniques in the same orientation in the same space. PET/CT and SPECT/CT devices provide hardware image fusion. However, patient motion can still cause misregistration that needs to be corrected. Software fusion has expanded the application of image fusion to many combinations of 3D image sets, including PET, SPECT, CT, and MRI. For example, a useful approach in young patients with neuroblastoma is to fuse ${ }^{123}$ I-MIBG SPECT and MRI. Fusion can also be used on images of the same modality acquired under different circumstances or at different times. In the assessment of patients with epilepsy, image fusion is used to compare 2 functional states, such as ictal and interictal brain perfusion. Similarly, registration of SPECT or PET with MRI is a useful approach to assist in the localization of epileptogenic cortex. Most methods allow rigid fusion that works well for brain studies. Nonrigid registration and fusion of organs in the chest and abdomen is possible but more challenging to implement because of deformations due to body motion between 2 image acquisitions.

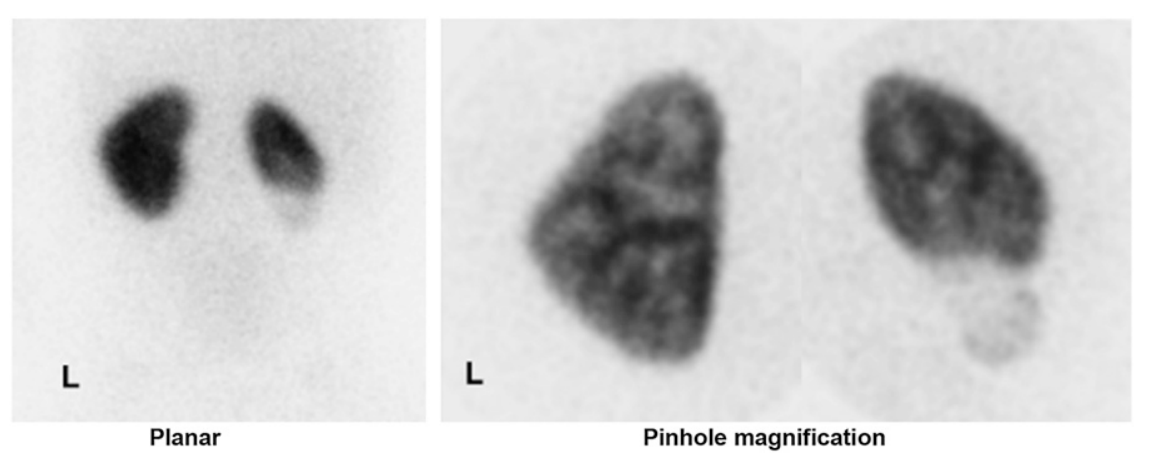

FIGURE 2. Renal duplication. 99mTc-DMSA posterior images from 5-wk-old boy with right renal duplication. (Left) Planar image with parallel-hole low-energy ultra-high-resolution collimator. (Right) In same patient, 2 individual pinhole images showing better spatial resolution. Detail of renal cortex and separation of right upper and lower renal moieties are much better defined. 


\section{Radiopharmaceuticals}

An important advantage of nuclear medicine in the first year of life is that it is extremely safe. Radiopharmaceuticals typically are nontoxic and nonallergenic. The total mass of material that is administered is small and does not elicit an osmotic effect. Similarly, the administered mass is low enough that no pharmacologic or toxic effect is produced. For example, a patient who is allergic to iodine can safely receive ${ }^{123} \mathrm{I}-\mathrm{NaI}$ or ${ }^{123} \mathrm{I}-\mathrm{MIBG}$ because the administered mass of iodine is well below the threshold needed to trigger an allergic effect. The volume and mass of a radiopharmaceutical that is administered is significantly lower than that of MRI and CT contrast agents. For example, in a 10-kg 1-y-old patient having a bone scan, the administered volume of ${ }^{99 \mathrm{~m} T c-M D P}$ solution is $0.06 \mathrm{~mL}$ containing only $0.64 \mathrm{mg}$ of radiopharmaceutical. In comparison, for the same 10-kg patient undergoing MRI, $940 \mathrm{mg}$ of gadopentetate dimeglumine (Magnevist; Bayer) may be administered in a volume of $2.0 \mathrm{~mL}$. For a contrast-enhanced CT scan, $6,400 \mathrm{mg}$ of ioversol (Optiray 320; Covidien) may be administered in a volume of $20 \mathrm{~mL}$. Thus, the administered volume for ${ }^{99 \mathrm{~m}} \mathrm{Tc}-$ MDP is 20- to 200-fold less than that for MRI or CT contrast agents, and the administered mass is more than a thousandfold less (Table 1).

Pediatric radiopharmaceutical doses in neonates and infants should be determined by the minimum amount of activity necessary to ensure a satisfactory diagnostic examination in the shortest time. Administered doses that are too high lead to increased radiation dose to the patient without resulting in improved diagnostic sensitivity or accuracy. Doses that are too low may not permit an adequate examination. In both cases, too-high or too-low doses lead to unnecessary radiation exposure. In adult patients, dosing is roughly standardized. However, in most pediatric patients this has not been the case. Pediatric activity doses are often scaled down from the adult dose on the basis of body weight, surface area, size, or age. These dose estimations for pediatric patients based on adult dose corrected for body weight or body surface area are usually adequate for children over $1 \mathrm{y}$ old. Presently, there is no universally accepted guideline for administered radiopharmaceutical doses in children (5). Different approaches to determining administered dose have accounted for substantial variations among centers. Two common methods use patient size as determined by the patient's weight or surface area: Clark's rule and the area

TABLE 1

Comparison of Mass and Volumes for Certain Radiopharmaceuticals and Contrast Agents

\begin{tabular}{lcc}
\hline \multicolumn{1}{c}{ Agent } & Volume $(\mathrm{mL})$ & Mass $(\mathrm{mg})$ \\
\hline 99mTc-MDP & 0.06 & 0.64 \\
99mTc-DMSA & 0.03 & 0.22 \\
99mTc-MAG3 & 0.10 & 1.1 \\
Gadopentetate dimeglumine & 2.0 & 940 \\
loversol & 20 & 6,400 \\
\hline
\end{tabular}

rule. Other methods use age as the predominating factor in dose calculation: Young's rule, Webster's rule, and Fried's rule. The dosage method used at a particular clinic is largely dependent on the practitioner's preferences. Premature infants and newborns require special consideration, and one needs to consider the concept of minimum administered dose- the amount of administered radiopharmaceutical below which the study will be inadequate regardless of the patient's size (1).

We recently surveyed 13 dedicated pediatric hospitals in North America to determine radiopharmaceutical dose schedules for 16 commonly performed nuclear medical studies. The survey also inquired about minimum and maximum administered activity for each procedure. In our survey, we found that scaling the adult radiopharmaceutical doses according to the patient's weight is a common approach. This approach leads to similar radiation-absorbed doses to the patient irrespective of patient size because the radiation dose is defined as energy imparted per unit mass. When dosing is determined according to weight, the differences in patient geometric factors such as the size and shape of the individual organs and distance between organs actually lead to smaller patients receiving a slightly smaller radiation dose than larger patients (Table 2). From our survey, the average administered activity per body mass varied by a factor of 3 , and the variation was by as much as a factor of 10 among the institutions. On the other hand, the variation in minimum administered activity was a factor of 10 on average and was as much as a factor of 20. Thus, the greatest variability in administered dose is in the smallest patients. This fact suggests that an opportunity exists to reexamine and redefine the lowest administered doses that ensure satisfactory studies in patients in this age group. The European Association of Nuclear Medicine has also developed a pediatric dose card (6).

As a result of that survey, during 2009 and 2010, a pediatric nuclear medicine group organized consensus conferences and workshops that included many pediatric nuclear medicine physicians, physicists, and technologists from North America. This group included representatives from the Society of Nuclear Medicine, the Society for Pediatric Radiology, the American College of Radiology, and the Image Gently Campaign. This group's activity has recently produced a new consensus guideline for pediatric radiopharmaceutical administered doses. This guideline, which has been approved by the Society of Nuclear Medicine and the Society for Pediatric Radiology, narrowed the variation in pediatric radiopharmaceutical doses, addressing the minimum administered doses for the smallest patients, as well as doses per kilogram of body weight (7).

\section{Reduction of Radiation Exposure and Risk}

In general, nuclear medicine procedures involve exposure to relatively low levels of ionizing radiation. The diagnostic value of these procedures, when used appropriately, far outweighs potential radiation exposure and thus potential risk. However, younger individuals may be at a higher risk than adults for long-term effects from radiation, 
TABLE 2

Effective Dose for Selected Pediatric Nuclear Medicine and Radiographic Procedures

\begin{tabular}{|c|c|c|c|c|}
\hline \multirow[b]{2}{*}{ Procedure } & \multirow[b]{2}{*}{ Activity $(\mathrm{MBq})^{\star}$} & \multicolumn{3}{|c|}{ Effective dose (mSv) } \\
\hline & & Newborn (3.6 kg) & 1-y-old infant $(9.7 \mathrm{~kg})$ & 5-y-old child (19.8 kg) \\
\hline 99mTc-DMSA scanning & 111 & $0.50\left(0.65^{\dagger}\right)$ & 0.58 & 0.68 \\
\hline 99mTc-MAG3 scanning & 370 & $0.94\left(1.82^{\dagger}\right)$ & 1.11 & 1.27 \\
\hline 99mTc-MDP scanning & 740 & 2.74 & 2.93 & 3.14 \\
\hline${ }^{123}$ I-MIBG scanning ${ }^{\ddagger}$ & 370 & - & 3.49 & 3.87 \\
\hline${ }^{131}$ |-MIBG scanning ${ }^{\S}$ & 37 & - & 5.64 & 6.38 \\
\hline${ }^{18} \mathrm{~F}-\mathrm{NaF}$ scanning ${ }^{\S}$ & 148 & - & 3.49 & 3.60 \\
\hline${ }^{18} \mathrm{~F}-\mathrm{FDG}$ scanning & 370 & 5.00 & 5.38 & 5.85 \\
\hline $\begin{array}{l}\text { Chest radiography } \\
\text { (anteroposterior and lateral) }\end{array}$ & & 0.01 & 0.01 & 0.01 \\
\hline Abdominal CT & & 5.0 & 4.5 & 4.0 \\
\hline \multicolumn{5}{|c|}{ 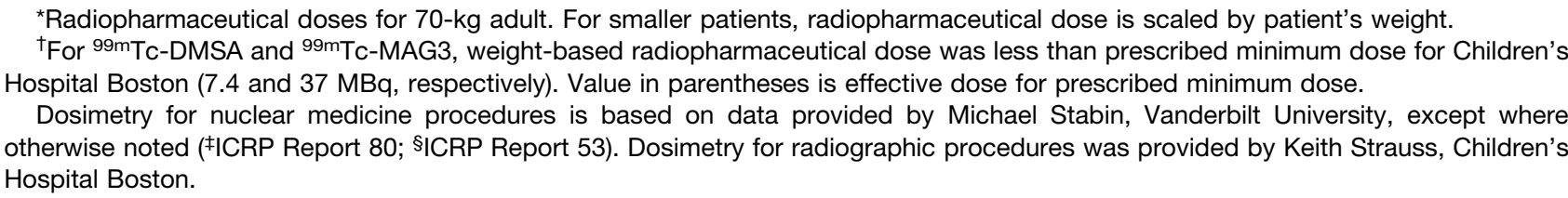 } \\
\hline
\end{tabular}

partly because of the higher sensitivity of growing tissues in young individuals and because they have more potential years of life ahead during which the risk could be realized. When the administered doses are scaled by body weight, the range of effective doses for nuclear medicine procedures is $0.6-5.5 \mathrm{mSv}$ and comparable to that from other common imaging procedures $(8,9)$. A precise estimate of radiation dose requires knowledge of the administered dose, the size or geometry of the patient, and the biokinetics of the radiopharmaceutical. When radiopharmaceutical doses are scaled by body weight, the increasing radiation sensitivity for younger patients is partly offset by the lower radiation dose, and thus the total risk is reasonably constant across pediatric age groups (Table 3).

One way to achieve the lowest radiation exposures in pediatric nuclear medicine is to ensure that the requested procedure is the most appropriate for the specific diagnostic question and that the administered dose is appropriate for the specific diagnostic imaging task. Therefore, it is important to obtain sufficient clinical information on each case before proceeding with a study. The minimum administered dose of activity to be given to a child is determined by the type of study: dynamic or static. Rapid dynamic studies require a higher dose of tracer than static studies for sufficient image count statistics.

As an example, certain studies (e.g., hepatobiliary studies or ${ }^{99 \mathrm{~m}} \mathrm{Tc}-m e r c a p t o a c e t y l t r i g l y c i n e ~[M A G 3]$ renal scans) have traditionally included an initial radionuclide angiogram at 1-3 frames/s during the first $60 \mathrm{~s}$ of the study, followed by a longer acquisition with approximately 1-4 frames/min. One should consider the clinical need to routinely acquire a radionuclide angiogram at rapid framing rates, or if the study interpretation could be adequately achieved with images acquired for 1-2 min each. Therefore, slow dynamic studies (e.g., hepatobiliary scintigraphy or dynamic renal scintigraphy) that do not require high temporal resolution can be obtained satisfactorily with a lower administered activity than studies requiring rapid framing rates, thus resulting in relatively lower patient radiation dose. Therefore, appropriate adjustments of acquisi-

TABLE 3

Comparison of Risk at Different Ages from 99mTc-MAG3 and Abdominal CT Studies

\begin{tabular}{|c|c|c|c|c|}
\hline Age (y) & Administered dose (MBq) & 99mTc-MAG3 effective dose (mSv) & 99mTc-MAG3 risk (\%) & Abdominal CT risk (\%) \\
\hline 0 (newborn) & 19 & 0.94 & 0.03 & 0.17 \\
\hline 1 & 51 & 1.11 & 0.04 & 0.11 \\
\hline 5 & 104 & 1.27 & 0.03 & 0.09 \\
\hline 10 & 175 & 2.09 & 0.05 & 0.08 \\
\hline 15 & 300 & 2.78 & 0.05 & 0.07 \\
\hline 20 & 370 & 2.87 & 0.04 & 0.06 \\
\hline 40 & 370 & 2.87 & 0.02 & 0.02 \\
\hline
\end{tabular}

This table is based on data provided by S. James Adelstein, Harvard Medical School. 
FIGURE 3. Low-dose hepatobiliary scintigraphy. Images were obtained with $\gamma$-camera equipped with parallel-hole low-energy ultra-high-resolution collimator using only $5.55 \mathrm{MBq}(0.15 \mathrm{mCi})$ of $99 \mathrm{mTc}$-disophenin. Images clearly demonstrate a choledochal cyst.

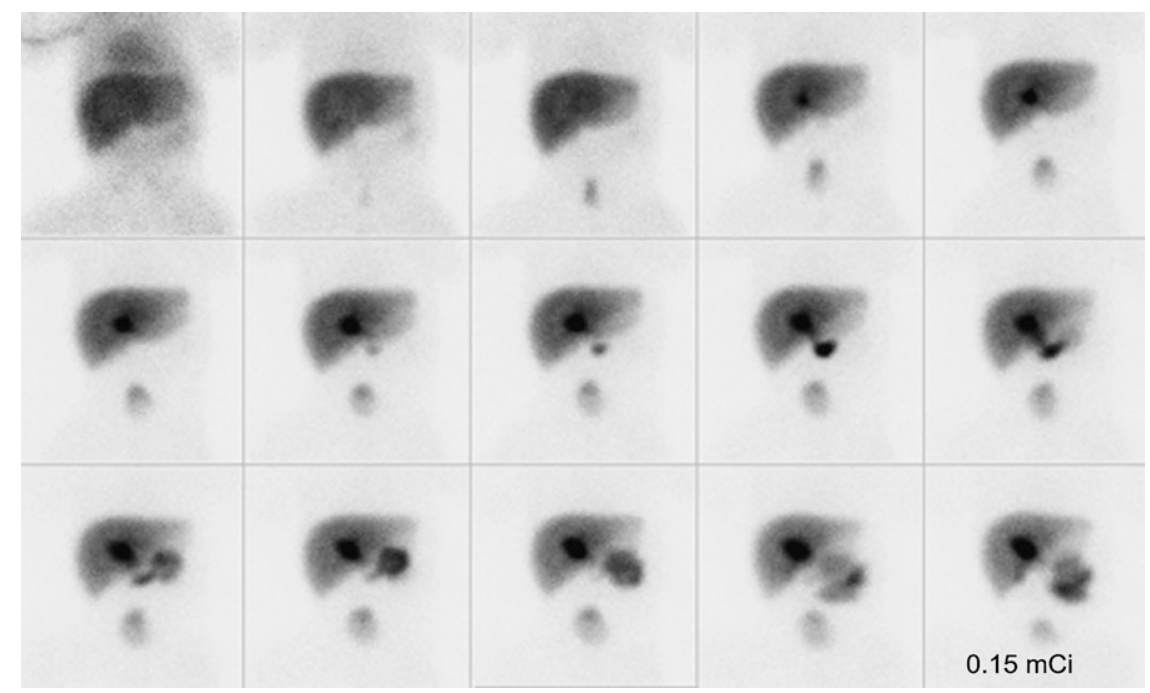

tion protocols may allow the administration of a lower radiopharmaceutical dose without degradation of image quality or diagnostic value (Fig. 3).

Because the anteroposterior cross-section of an infant is small $(8-10 \mathrm{~cm})$, another option that can be considered for reducing administered doses is the use of a low-energy high-sensitivity collimator, which may provide an appropriate resolution at these short depths. Another approach to reducing the dose is the application of advanced image processing techniques. Iterative reconstruction makes SPECT more feasible in these small patients. Unlike filtered backprojection techniques, iterative reconstruction can incorporate corrections for the noise properties of the projection data, as well as changes in collimator resolution with distance, leading to a more accurate reconstruction. These iterative reconstruction techniques provide similar, and often improved, image quality with significantly fewer counts needed to produce diagnostic quality images. Therefore, high-quality studies can be obtained with lower radiation exposure to the patient, shorter imaging times, or a combination of both. In addition, advanced planar processing allows a reduction in administered radiopharmaceutical doses without loss of diagnostic information. Performing SPECT reconstruction with 3D ordered-subset expectation maximization and with resolution recovery methods can significantly reduce the image acquisition time and make it possible to acquire a high-quality SPECT study of an infant in only a few minutes (Fig. 4) (10-14). The utility of iterative reconstruction and sophisticated filtering in the newborn and infant is under evaluation.

Although iterative reconstruction has been used in PET, incorporation of the spatial resolution variation within the field of view into the algorithm is relatively new. In addition, the use of 3D PET is most appropriate to very small children. 3D PET leads to a large gain in sensitivity relative to 2D PET. Thereby, the use of 3D PET in these patients should lead to PET studies of outstanding image quality in either a shorter imaging time or with less administered activity, depending on the diagnostic task. Newer PET systems that offer high spatial resolution across the field of view, improved field uniformity, faster imaging times, and improved imaging processing have obvious advantages for imaging small children. The use of these systems may allow a reduction in administered doses and thus a reduction of patient radiation exposure or of the need for sedation. An approach leading to reduction in radiation exposure suggests that it is possible to obtain adequate ${ }^{18} \mathrm{~F}-$ FDG brain PET images of term and preterm babies using $3.7 \mathrm{MBq}(0.1 \mathrm{mCi}) / \mathrm{kg}(15)$. This is lower than the current usual administered doses for this study (minimum, 5.18 $\mathrm{MBq}[0.14 \mathrm{mCi}] / \mathrm{kg}$, and maximum, $7.4 \mathrm{MBq}[0.20 \mathrm{mCi}] / \mathrm{kg}$, with a mean of $5.66 \mathrm{MBq}[0.153 \mathrm{mCi}] / \mathrm{kg})(7,16)$. Another way to reduce radiation exposure in children who are can-
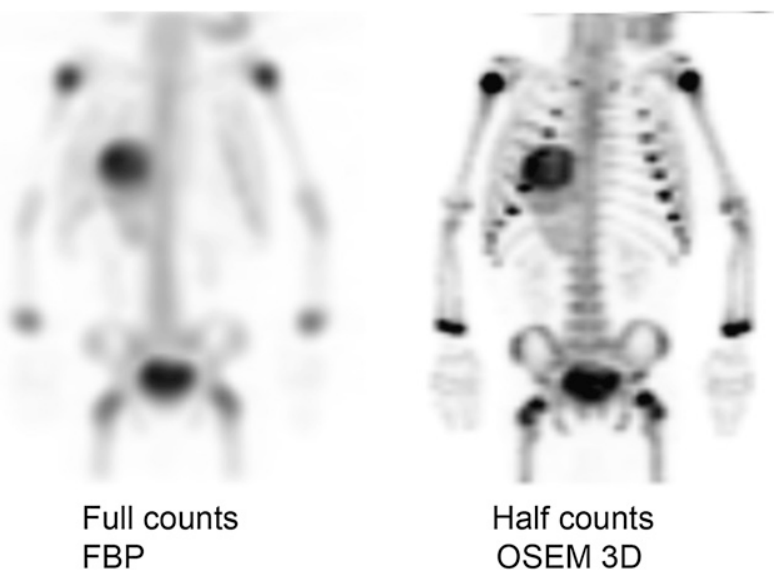

FIGURE 4. Advanced image processing. In 9-mo-old infant, SPECT images obtained $4 \mathrm{~h}$ after administration of $99 \mathrm{mTc}$-MDP. (Left) Maximum-intensity projection of SPECT obtained with parallel-hole low-energy ultra-high-resolution collimator reconstructed with conventional filtered backprojection (FBP). (Right) Maximumintensity projection of same study reconstructed with half counts using 3D ordered-subset expectation maximization (OSEM) with resolution recovery. Improvement of image resolution at half counts is remarkable. 
didates for PET/CT or SPECT/CT is to consider the use of previously acquired diagnostic CT for image fusion and not repeat the $\mathrm{CT}$ at diagnostic levels of radiation during the PET acquisition. CT during PET/CT or SPECT/CT can then be obtained at much lower doses for attenuation correction or anatomic correlation only. Software can then be used to fuse the $3 \mathrm{D}$ image sets.

\section{CLINICAL APPLICATIONS}

The second part of this review will discuss specific nuclear medicine studies that typically are obtained for patients in this age group. These include a full range of nuclear medicine studies, including oncologic studies and studies of the brain, thyroid, heart, lungs, liver, gastrointestinal tract, kidneys and genitourinary tract, spleen, lymphatic system, and skeleton.

\section{Brain and Cerebrospinal Fluid}

Frequent indications for brain SPECT, PET, and planar scintigraphy during the first year of life include seizures, tumors, effect of hypothermia and hypoxia, evaluation of cerebrospinal fluid flow, and assistance in the determination of brain death. An important consideration in this age group is brain immaturity and development. As the brain matures, regional cerebral blood flow and metabolic patterns change with age and follow the order of anatomic, evolutional, and behavioral development of the child. These changes are reflected on ${ }^{99 \mathrm{~m}} \mathrm{Tc}$-ethylcysteinate dimer (ECD) or exametazime perfusion brain SPECT and ${ }^{18} \mathrm{~F}-\mathrm{FDG}$ brain PET (Fig. 5). In the newborn, regional cerebral perfusion and regional metabolism are initially more intense in the sensorimotor cortex, thalamus, brain stem, and cerebellar vermis. Later, the parietal, temporal, and occipital cortex; basal ganglia; cerebellar cortex; and finally the frontal cortex are included. The level of cerebral glucose metabolism is lower in the newborn than in adults but increases with age. The pattern of ${ }^{18}$ F-FDG uptake in the pediatric brain becomes similar to that of young adults by $1 \mathrm{y}$ old. However, further brain development continues over several years. At about 3 y old, a child's brain metabolic activity exceeds that of an adult, and by approximately the age of 7 a plateau is reached with a value 1.3 times higher than in adults. The pattern of uptake and distribution of ${ }^{18}$ F-FDG in the brain is much lower in the thalamus and basal ganglia, cerebellum, sensorimotor cortex, frontotemporal, and occipital regions in preterm infants than in term infants (17-19).

In infants with intractable seizures, ictal and interictal perfusion brain and $99 \mathrm{~m}$ Tc-ECD SPECT aid in the localization of epileptogenic cortex. Ictal SPECT usually reveals increased local uptake in the epileptogenic region, whereas interictal SPECT shows regional reduction in cerebral perfusion within the same region. Ictal-minus-interictal subtraction of perfusion SPECT assists further in the localization of epileptogenic cortex.

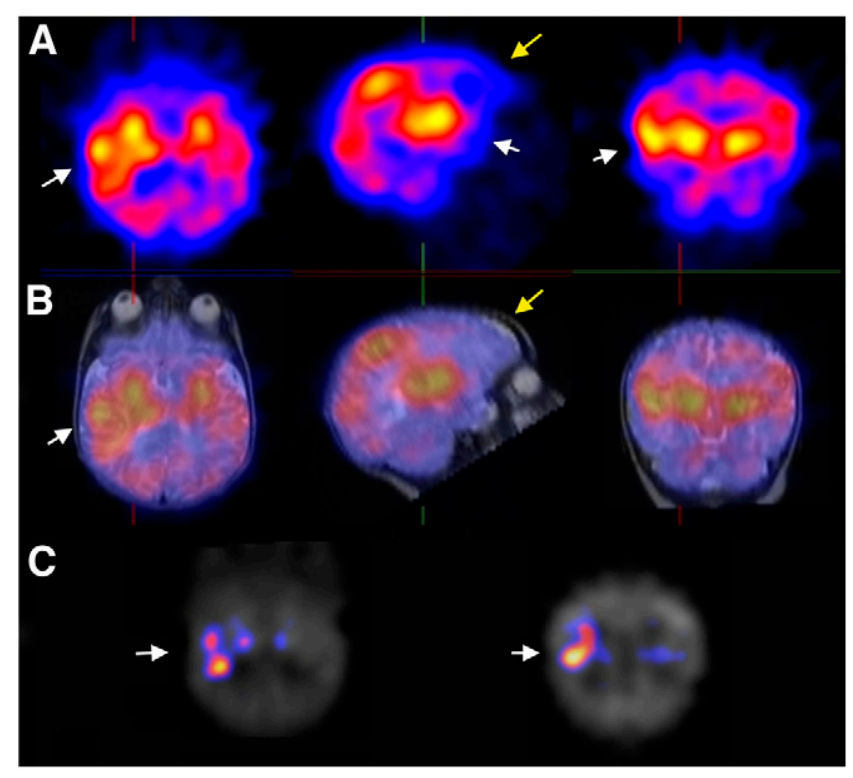

FIGURE 5. Brain immaturity and seizures. Two-month-old baby with 20-45 seizures per day. (A) Ictal SPECT shows increased perfusion in right posterior temporal region (white arrows), with low perfusion in frontal lobe due to immaturity (yellow arrow). (B) lctal SPECT fused with MRI. (C) Subtraction ictal-from-interictal SPECT shows increased differential perfusion in right posterior temporal area (arrows). Ictal ${ }^{18} \mathrm{~F}-\mathrm{FDG}$ PET showed increased uptake in right posterior temporal area. Original MRI findings were normal.

${ }^{99 m}$ Tc-ECD is a lipophilic agent that after intravenous injection rapidly concentrates in the brain at approximately $6 \%$ of the administered dose. This agent is a first-pass indicator and does not redistribute after its initial brain localization. Imaging can begin 5-10 min after the intravenous injection of the tracer or can be obtained a few hours (3-5 h) afterward, allowing the patient to be stabilized before imaging if needed. Typical administered doses are 7.4-11.1 MBq $(0.2-0.3 \mathrm{mCi}) / \mathrm{kg}$, with a minimum dose of $37 \mathrm{MBq}(1 \mathrm{mCi})$. In the interictal state, care should be taken to reduce environmental stimulation during the intravenous injection of the tracer. Ictal perfusion SPECT requires that the patient be given the tracer during a seizure. Successful ictal perfusion SPECT requires meticulous attention to detail and coordination (20). If the tracer is injected after the seizure activity has subsided, the resultant SPECT image depicts postictal regional cerebral blood flow and makes localization of a primary epileptogenic focus difficult.

${ }^{18}$ F-FDG PET is a useful method to localize epileptogenic cortex and to assess tumor viability. Active tumors show increased tracer uptake. However, it is well known that uptake of ${ }^{18} \mathrm{~F}-\mathrm{FDG}$ within normal brain tissue can interfere with the detection of tumor activity. Usual administered doses for ${ }^{18} \mathrm{~F}-\mathrm{FDG}$ for brain PET are $5.18 \mathrm{MBq}$ $(0.14 \mathrm{mCi}) / \mathrm{kg}$ at a minimum, with a mean of $5.66 \mathrm{MBq}$ $(0.153 \mathrm{mCi}) / \mathrm{kg}$. However, it has been shown possible to obtain adequate ${ }^{18} \mathrm{~F}$-FDG brain PET images in term and preterm babies using $3.7 \mathrm{MBq}(0.1 \mathrm{mCi}) / \mathrm{kg}(15) .{ }^{18} \mathrm{~F}-$ FDG PET is performed $1 \mathrm{~h}$ after intravenous administration 
of the tracer. Images can be obtained in 10 min or less using a 3D PET acquisition mode.

Interictal ${ }^{18} \mathrm{~F}$-FDG PET usually reveals regional decreased tracer uptake. Fusion of ictal-interictal subtraction SPECT images to MRI is helpful in localizing the seizure onset and in guiding the intracranial recording in childhood epilepsy (Figs. 5 and 6). Image fusion improves sensitivity and makes interpretation easier $(21,22)$. In the event that the patient has a seizure during the ${ }^{18} \mathrm{~F}-\mathrm{FDG}$ uptake period, the PET scan will demonstrate increased tracer uptake in the epileptogenic zone. This is rarely seen, as it is not possible to predict seizure activity during the hour or so of the ${ }^{18} \mathrm{~F}-\mathrm{FDG}$ brain uptake period. Therefore, most ${ }^{18} \mathrm{~F}-\mathrm{FDG}$ PET studies in patients with epilepsy are interictal.

For SPECT, it is important to ensure that the patient lies still for the examination and that the $\gamma$-camera detectors are positioned as close to the head as possible. We recommend the use of a dual-detector system equipped with ultra-highresolution collimators. Each detector rotates $360^{\circ}$ around the patient's head and records 120 images of $15 \mathrm{~s}$ each in a $128 \times 128$ matrix. In our experience, sedation is usually needed for brain SPECT or PET in many of these very young patients. Cerebrospinal fluid flow can be evaluated effectively with radionuclide cisternography in case of diversionary shunts and in the prechemotherapy assessment of cerebrospinal fluid flow (23).

\section{Thyroid}

Thyroid scintigraphy is useful in the evaluation of hypothyroidism in infants. Thyroid hormone is essential for the normal development of the central nervous system. Untreated congenital hypothyroidism is one of the most common preventable causes of mental retardation (24). Causes of neonatal hypothyroidism include thyroid agenesis, dysgenesis, or ectopia (25); dyshormonogenesis due to inborn errors in thyroid hormone synthesis $(26,27)$; and transient infantile hypothyroidism caused by maternal thyroid-blocking antibodies, maternal antithyroid medications, or iodine exposure (28). In North America, congenital hypothyroidism has an incidence of approximately 1 in every 3,000-4,000 births, with approximately a 2:1 female predominance $(24,27)$. Nearly all new cases of infantile hypothyroidism in North America and Europe are now detected by neonatal laboratory screening for hypothyroidism, which facilitates prompt evaluation and early institution of thyroid hormone replacement therapy to prevent neurocognitive damage.

During embryonal development, the thyroid gland arises from endodermal tissue at the floor of the oropharynx and descends along the thyroglossal duct from the pharynx to the neck. A remnant thyroglossal duct may be seen as a pyramidal lobe, persistent duct, or thyroglossal cyst. With disrupted migration, ectopic thyroid tissue may lie anywhere along the migratory pathway from the base of the tongue to the thyroid bed, or even into the mediastinum (29). The relationship between abnormal thyroid migration and dysfunction is poorly understood. In some individuals

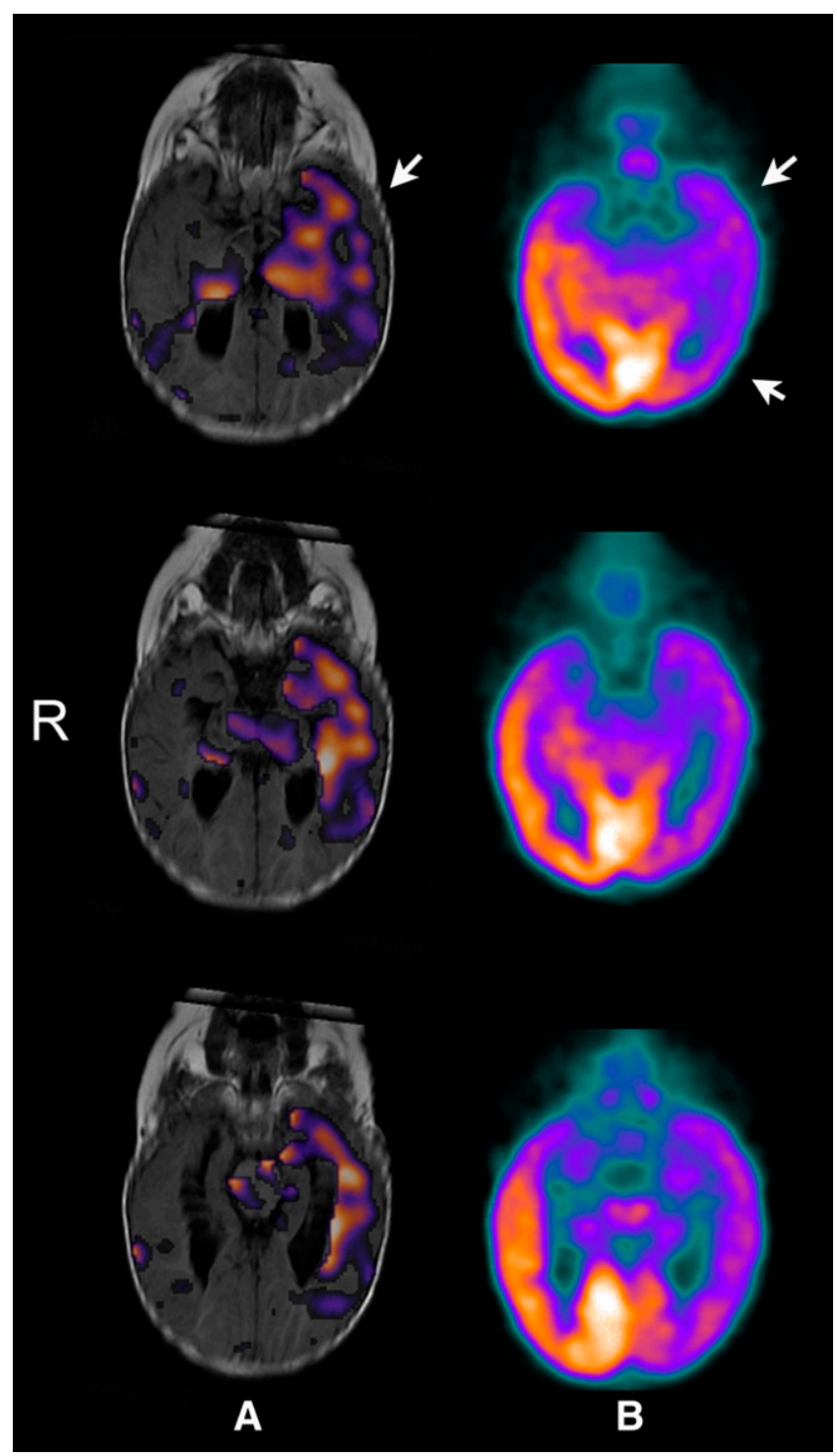

FIGURE 6. Seizure. In 11-y-old boy with left temporal seizure activity, subtraction of ictal from interictal perfusion $99 \mathrm{mTc}-\mathrm{ECD}$ SPECT fused with MRI shows ictal activity in left temporal region (arrow, A), and ${ }^{18} \mathrm{~F}-\mathrm{FDG}$ PET reveals more extensive region of reduced tracer uptake in left side of brain (arrows, B).

an ectopic thyroid may produce thyroid hormone; in others, an ectopic thyroid may be dysgenic or show diminished function. Thyroid dyshormonogenesis can result from many different inborn errors of metabolism of thyroid hormone synthesis. Transient hypothyroidism is a clinical diagnosis, and the affected infant may not even be referred for imaging studies. Patients may be referred for nuclear medicine evaluation to exclude concurrent thyroid dysgenesis or ectopia. Because the neonatal brain is dependent on thyroid hormone for normal development, thyroid hormone replacement should not be discontinued during nuclear medicine evaluation of the thyroid (28-30).

Nuclear medicine and ultrasound are complementary for the evaluation of infantile hypothyroidism. Thyroid scintig- 
raphy is highly sensitive for detection of ectopic thyroid tissue, and ultrasound is useful for evaluation of the gland size and morphology. Ultrasound may be helpful for confirming the presence of nonfunctioning thyroid tissue of patients with thyroid suppression due to hormone replacement therapy, recent nonradioactive iodine overload, thyroidstimulating hormone deficiency, or maternal thyroid-blocking antibodies (31).

Functional imaging of the thyroid gland can be obtained with either ${ }^{99 \mathrm{~m}} \mathrm{Tc}$-pertechnetate or radioiodine. ${ }^{123} \mathrm{I}$ is the radioisotope of choice for imaging the infant's thyroid. For pediatric thyroid imaging, a typical dose of ${ }^{123} \mathrm{I}$ is $0.9 \mathrm{MBq}$ $(0.025 \mathrm{mCi})$. In an infant, the average thyroid dose is predicted to be less than $5 \mathrm{mSv} / \mathrm{MBq}(18.5 \mathrm{rem} / \mathrm{mCi})(30,32)$. Although ${ }^{99} \mathrm{~m}$ Tc-pertechnetate accumulates in the thyroid gland, it is not organified and can wash out of the thyroid. This method of thyroid imaging has been popular because of the ready availability of ${ }^{99 \mathrm{~m}}$ Tc-pertechnetate and the ability to image the thyroid immediately after intravenous administration of the tracer. For pediatric thyroid imaging, a typical dose of ${ }^{99 \mathrm{~m} T c}$-pertechnetate is $1.1 \mathrm{MBq}(0.03 \mathrm{mCi}) / \mathrm{kg}$, with a minimum dose of $7.5 \mathrm{MBq}(0.2 \mathrm{mCi})$. However, compared with ${ }^{123} \mathrm{I},{ }^{99 \mathrm{~m}} \mathrm{Tc}$ assesses only the trapping function (30). Thyroid images are best obtained with a pinhole collimator, either to provide a magnified view of the thyroid by placing the collimator as close as possible to the neck or to provide a birds-eye view of a larger region to survey for ectopic thyroid tissue that may be anywhere between the oropharynx and mediastinum (30). Anatomic localization of functional thyroid tissue is facilitated by acquiring a transmission scan of the upper body to overlay with the diagnostic scan. Small radioactive sources are used to mark anatomic landmarks.

\section{Lungs}

Pulmonary ventilation and perfusion studies are indicated in several conditions in patients less than 1 y old: pneumonia, inflammation, or infection; cyanosis; lobar emphysema; assessment of pulmonary artery angioplasty or surgery; congenital diaphragmatic hernia and repair; bronchopulmonary dysplasia; foreign bodies; aspiration; asthma; pulmonary hypoplasia, stenosis, aplasia, or agenesis; pulmonary sequestration; pulmonary embolism; pulmonary valve stenosis; arteriovenous malformation; and evaluation of pulmonary transplants. Pulmonary perfusion scintigraphy is useful as part of the overall cardiopulmonary assessment of patients before and after catheter interventions, intravascular stent placement, occlusion of unwanted vascular communications, surgical arterioplasty, and other surgical interventions in patients with congenital or acquired heart disorders (Fig. 7). Frequently, patients with congenital heart disease referred for assessment of pulmonary perfusion have a right-to-left shunt of various levels of severity, as demonstrated by systemic penetration of macroaggregated particles. This condition is the result of microembolization of all the systemic organs and is most prominently appreciated in organs with high relative blood flow (e.g., the

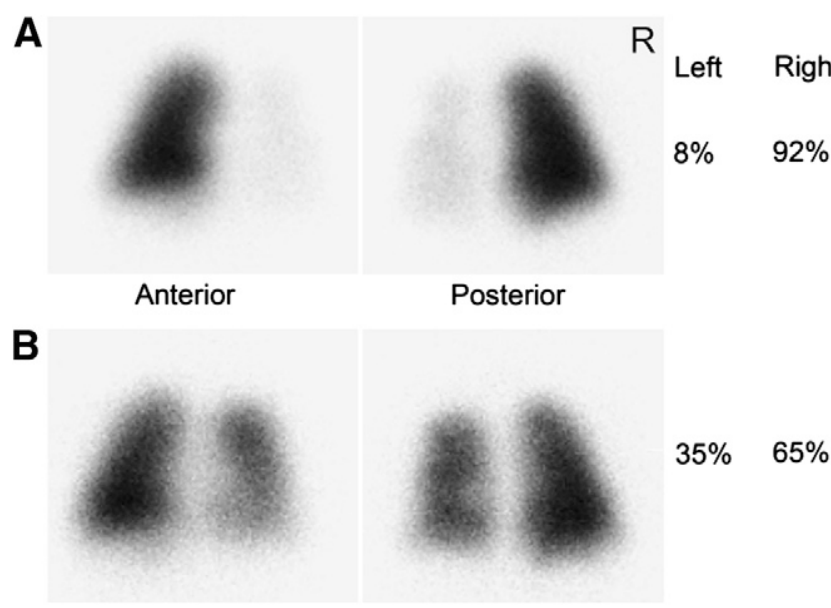

FIGURE 7. Pulmonary blood flow and vascular intervention. Pulmonary perfusion scintigraphy of baby with tetralogy of Fallot. (A) Initial pulmonary blood flow was $8 \%$ for left lung and $92 \%$ for right lung. (B) After pulmonary angioplasty and placement of stent, left lung had increased to $35 \%$ of total pulmonary blood flow.

brain and kidneys). The pulmonary-to-systemic flow ratio is lower than 1:1 and can be calculated by determination of the relative pulmonary and systemic activity on a wholebody scan. The biologic half-life of ${ }^{99 \mathrm{~m} T c-m a c r o a g g r e-}$ gated albumin in the lungs is approximately $6 \mathrm{~h}$. Once trapped in the pulmonary arterioles, ${ }^{99 \mathrm{~m}} \mathrm{Tc}$-macroaggregated albumin particles are degraded into smaller particles and polypeptides, which are taken up by the liver and ultimately eliminated in bile. Although macroaggregated particles are rapidly cleared and are considered safe in patients with right-to-left shunts, it seems prudent to minimize systemic microembolization by reducing the number of administered particles without compromising diagnostic yield.

The pulmonary vasculature of infants shows a rapid increase from approximately a tenth to a third of the adult values during the first year of life and reaches approximately half the adult number by the age of $3 \mathrm{y}$. Although administration of $\pm 500,000{ }^{99 \mathrm{~m}} \mathrm{Tc}$-macroaggregated albumin particles is considered safe in an adult, the number of injected particles should not exceed 50,000 or 165,000 in a 1-y-old child (33). In our routine practice, we use fewer than 10,000 particles in neonates and infants, as well as in all patients with right-to-left shunts and in patients with pulmonary hypertension or severe pulmonary disease (Table 4). Because pulmonary ventilation studies can be obtained rapidly and effectively using ${ }^{133} \mathrm{Xe}$ gas even in the smallest patients, air trapping can be documented and ventilation perfusion ratios can be calculated (34).

\section{Heart}

Although nuclear cardiology is not frequently performed on children, it is useful in several cases. Indications for pediatric nuclear cardiology in children during the first year of life include the following: Kawasaki disease; repair of tetralogy of Fallot; an anomalous left coronary artery departing from the pulmonary artery; a postarterial switch operation; 
TABLE 4

Usual Administered Doses of 99mTc-Macroaggregated Albumin

\begin{tabular}{lcccccc}
\hline \multicolumn{1}{c}{ Parameter } & Newborn & $1 \mathrm{y}$ & $5 \mathrm{y}$ & $10 \mathrm{y}$ & $15 \mathrm{y}$ & Adult \\
\hline Body weight $(\mathrm{kg})$ & 3.5 & 12.1 & 20.3 & 33.5 & 55 & 70 \\
Administered dose $(\mathrm{MBq})$ & $7.4(0.2 \mathrm{mCi})$ & $18.5(0.5 \mathrm{mCi})$ & $37(1.0 \mathrm{mCi})$ & $55.5(1.5 \mathrm{mCi})$ & $92.5(2.5 \mathrm{mCi})$ & $111(3.0 \mathrm{mCi})$ \\
Range of particles & $10-50$ & $50-150$ & $200-300$ & $200-300$ & $200-700$ & $200-700$ \\
$\quad$ administered $(\times 100)$ & & & & &
\end{tabular}

cardiomyopathies; cardiac transplantation; estimation of right ventricular pressure overload or right ventricular hypertension; left-to-right shunts; right-to-left shunts; and determination of left and right ventricular ejection fractions. Myocardial perfusion imaging is used in the evaluation of myocardial ischemia, infarction, and viability in young children with Kawasaki disease, an anomalous origin of the left coronary artery from the pulmonary artery, or coronary ectasia, and patients after the arterial switch operation for transposition of the great arteries can be evaluated noninvasively with myocardial perfusion imaging (Fig. 8) (35).

${ }^{99 \mathrm{~m}}$ Tc-methoxyisobutylisonitrile (MIBI) is a first-pass indicator that accumulates in the myocardium according to regional myocardial perfusion. After intravenous injection, this agent concentrates in several organs, including the thyroid, myocardium, kidneys, and striated muscle. The agent clears rapidly from the blood, with less than $8 \%$ of the administered activity remaining in blood at $5 \mathrm{~min}$, and less than $1 \%$ of the tracer is protein-bound in the plasma. The principal route of elimination of ${ }^{99 \mathrm{~m}} \mathrm{Tc}-\mathrm{MIBI}$ is the hepatobiliary system. Tracer activity appears in the intestine within the first hour after injection. At rest, approximately $1.5 \%$ of the injected dose is taken up in the myocardium, where it remains fixed, with no redistribution over time. With ${ }^{99 \mathrm{~m}} \mathrm{Tc}-$ MIBI, both resting and pharmacologic stress evaluations can be performed on children $(35,36)$.

In preparation for myocardial perfusion scintigraphy, the patient should fast for $2 \mathrm{~h}$ before administration of the tracer. A short intravenous catheter is placed and secured to the skin with tape, and the line is kept viable with normal saline. The intravenous line is maintained in place so it can be used to inject the tracer during pharmacologic stress. Because ${ }^{99 \mathrm{~m}}$ Tc-MIBI has no significant redistribution over a 4- to 6-h period, 2 injections of the radiopharmaceutical are used to obtain rest and stress myocardial perfusion imaging within the same day. For a single study (rest or stress) done alone, a dose of $37 \mathrm{MBq}(1 \mathrm{mCi})$ is used. If rest and stress studies are done on separate days, the same dose of ${ }^{99 \mathrm{~m}}$ Tc-MIBI can be used for the second study. For rest and stress studies performed on the same day, a $37-\mathrm{MBq}$ (1-mCi) dose is suggested for the rest ${ }^{99} \mathrm{~m}$ Tc-MIBI SPECT study; $2-4 \mathrm{~h}$ afterward, the stress study is performed using a dose of $74 \mathrm{MBq}(2 \mathrm{mCi})$ given at peak stress. Imaging is obtained $5 \mathrm{~min}$ after tracer administration. Acquisition protocols should be adapted to individual SPECT systems. SPECT may be acquired using the following parameters:
120 total projections (60 stops with a dual-detector system) over $180^{\circ}$ with a $128 \times 128$ matrix for a total of $20-30 \mathrm{~min}$. Electronic magnification is used according to the patient's heart size. After acquisition and reconstruction, the study is reoriented along the long axis of the left ventricle. Gated myocardial perfusion SPECT provides information on myocardial contractility, wall motion, end-diastolic and endsystolic ventricular volumes, ejection fraction, regurgitant fraction, and cardiac output.

Cardiac transplantation has become a treatment option for neonates, infants, and children with end-stage cardiomyopathy or those with congenital heart disease that cannot be treated by surgical palliation or repair. Early recognition of accelerated transplant vasculopathy could be achieved with myocardial perfusion scintigraphy. Collateral circulation occurs with some frequency and may be a factor affecting the detectability of myocardial perfusion abnormalities at rest. Most young children show adequate perfusion during the early postoperative period. Along with coronary angiography, myocardial perfusion SPECT helps in the diagnosis of coronary artery disease and myocardial viability (35).

Patients with an anomalous left coronary artery arising from the pulmonary artery have severe myocardial dysfunction and ischemia during early infancy. The left ventricle becomes perfused with desaturated blood and at coronary pressures that rapidly fall below systemic pressures. Classic complications include ischemia and infarction of the anterolateral left ventricular free wall, followed by mitral valve incompetence due to infarction of the anterior papillary muscle. This leads to congestive heart failure in the first year
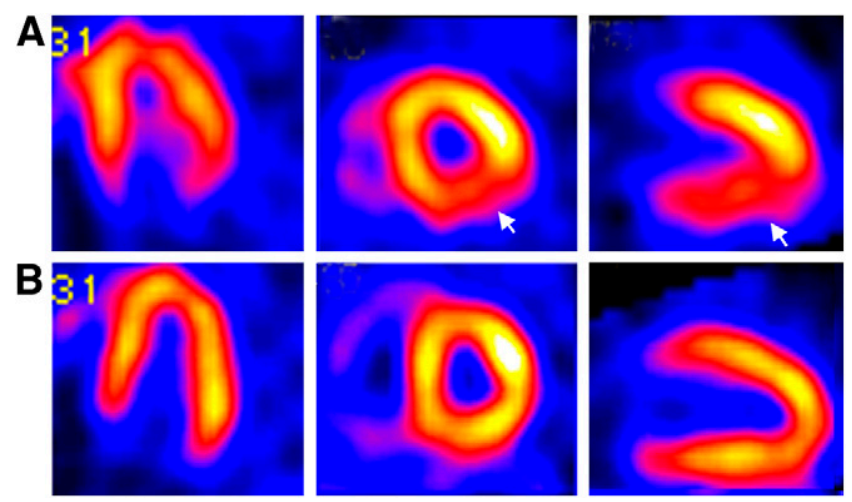

FIGURE 8. Kawasaki disease. Infant boy imaged with ${ }^{99 m T C-M I B I}$ SPECT. (A) Stress study reveals perfusion defect (arrows) in inferior wall of left ventricle. (B) Rest SPECT shows perfusion in same areas. 
of life. Several surgical techniques have been used to transfer the anomalous coronary artery back to the aortic cusp. Myocardial perfusion scintigraphy can assess ventricular wall damage and evaluate recovery of function after repair (35). Children with right ventricular hypertension or right ventricular overload show greater tracer uptake of myocardial perfusion agents in the right ventricular myocardium. The increased uptake correlates with peak right ventricular pressures (37).

\section{Left-to-Right Shunts}

The recommended procedures for detection and anatomic characterization of left-to-right shunts are ultrasound and MRI. Radionuclide methods have played a major role in the past and can be used to quantitate shunts $(38,39)$. ${ }^{99 m}$ Tc-pertechnetate is the most commonly used radiopharmaceutical. The patient should be premedicated with sodium perchlorate (intravenously) or potassium perchlorate (orally) to reduce thyroid uptake of the tracer. The recommended administered dose of ${ }^{99 \mathrm{~m}} \mathrm{Tc}$ is $74 \mathrm{MBq}(2$ $\mathrm{mCi}$ ). The total volume of radiopharmaceutical solution should not exceed $0.2 \mathrm{~mL}$ so that a small rapid intravenous bolus can be administered. Patients do not need sedation for this procedure. An intravenous needle (butterfly type, 2325 gauge) or a short intravenous catheter is inserted. Once one is assured that the needle or catheter is properly placed and that there is no possibility of extravasation, it should be secured to the patient's skin. If possible, an antecubital vein is selected for the injection. Other venous sites can be used as long as they are patent and can tolerate a rapid 1- to 3-mL saline flush. The patient is placed supine on the imaging table. The $\gamma$-camera, equipped with a parallel-hole, high-sensitivity collimator, is positioned over the patient's chest. The field of view extends from the suprasternal notch to just below the xyphoid and covers both pulmonary fields. Radionuclide angiocardiography for the assessment of leftto-right shunting is recorded at 2 or 4 frames/s for $25 \mathrm{~s}$ on a $128 \times 128$ matrix or in list mode. Injection technique is of utmost importance for quantitation of left-to-right shunts. The volume of saline flush should be approximately 1-3 $\mathrm{mL}$ in infants. The tracer should not be injected while the patient is crying or producing Valsalva maneuvers. Increase in intrathoracic pressure can cause bolus fragmentation and render the study inadequate. Injecting the tracer with the saline simultaneously allows rapid, uniform delivery of the tracer with uninterrupted saline flushing. If the radioactive bolus is fragmented, deconvolution analysis ensures a high percentage of successful studies.

Left-to-right shunts can be easily quantitated by analysis of the pulmonary time-activity curve in first-pass radionuclide angiography (Fig. 9). This method can accurately quantify left-to-right shunts of pulmonary-to-systemic flow ratios between 1.2 and $3.0(38,39)$. For determination of right and left ventricular ejection fraction, radionuclide angiocardiography should be recorded at a minimum rate of 25 frames per second for $25 \mathrm{~s}$ on a $128 \times 128$ matrix or in list mode.

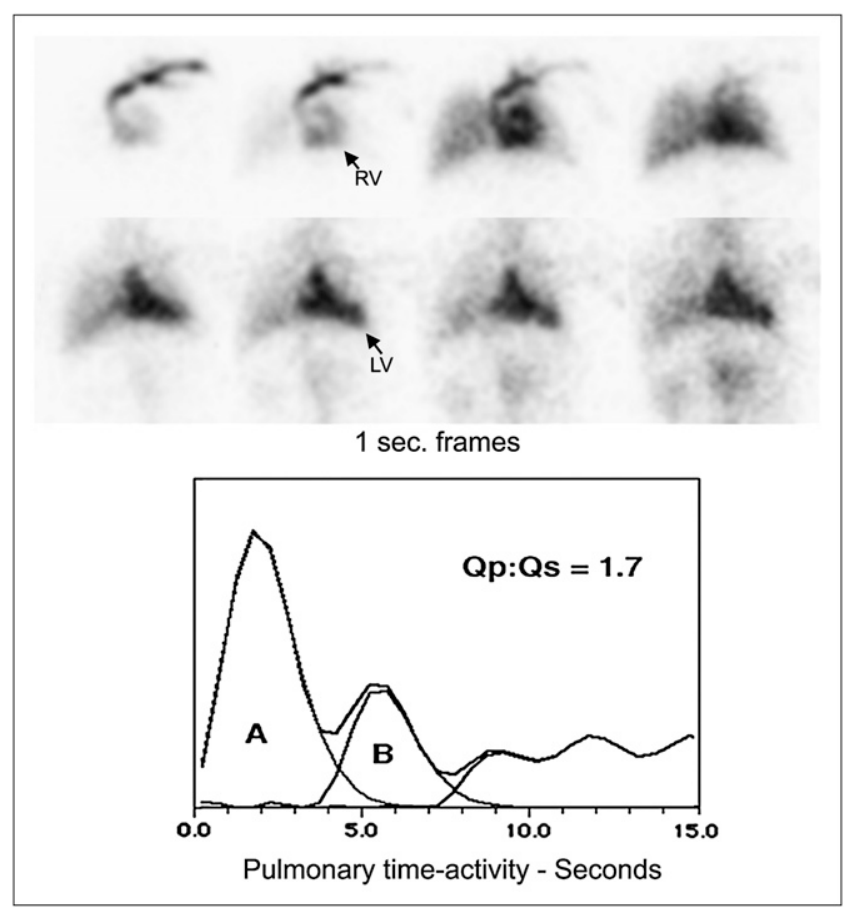

FIGURE 9. Left-to-right shunt. First-pass radionuclide angiogram of infant with pulmonary-to-systemic flow ratio (Qp:Qs) of 1.7. LV = left ventricle; $R V=$ right ventricle. $A=$ area under curve for first pulmonary circulation; $\mathrm{B}=$ area corresponding to early pulmonary recirculation ( $A / A-B=Q p: Q s)$.

Normal values of right and left ventricular ejection fractions using first-pass radionuclide angiocardiography have been determined in children (40).

\section{Hepatobiliary Indications}

The most frequent indications for hepatobiliary scintigraphy during the first year of life are the differentiation of biliary atresia from hepatocellular disease and the diagnosis of choledochal cysts. Hepatobiliary scintigraphy can exclude the diagnosis of biliary atresia by demonstrating biliary passage of the radiopharmaceutical into bowel. When this passage cannot be demonstrated, the diagnosis of biliary atresia is highly suspected (Fig. 10). The definitive diagnosis of biliary atresia requires percutaneous or intraoperative transhepatic cholangiography. Hepatobiliary scintigraphy repeated after a few days may be helpful in newborns in whom excretion of tracer in the bowel is not demonstrated on an early single examination.

In jaundiced infants, pretreatment with phenobarbital increases biliary secretion and facilitates the differentiation of neonatal hepatitis from biliary atresia. Phenobarbital is given for 3-5 d before hepatobiliary scintigraphy in doses of $5 \mathrm{mg} / \mathrm{kg} / \mathrm{d}(41)$. In neonatal jaundice, hepatobiliary scintigraphy after phenobarbital therapy is highly accurate for differentiating biliary atresia from other causes of neonatal jaundice. Hepatobiliary scintigraphy has $97 \%$ sensitivity and $82 \%$ specificity (91\% accuracy) in the diagnosis of biliary atresia. A simple visual grading that includes the 
A

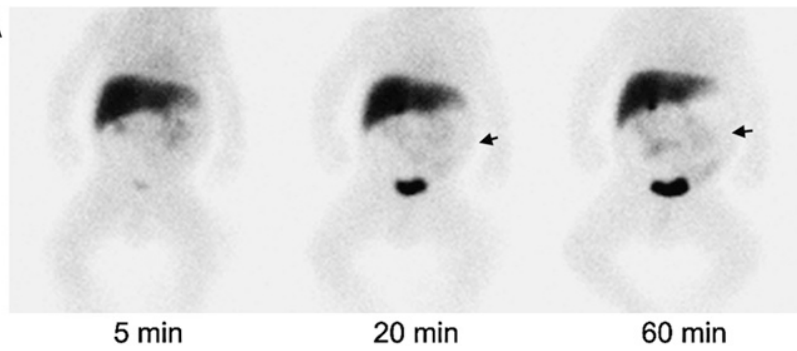

B

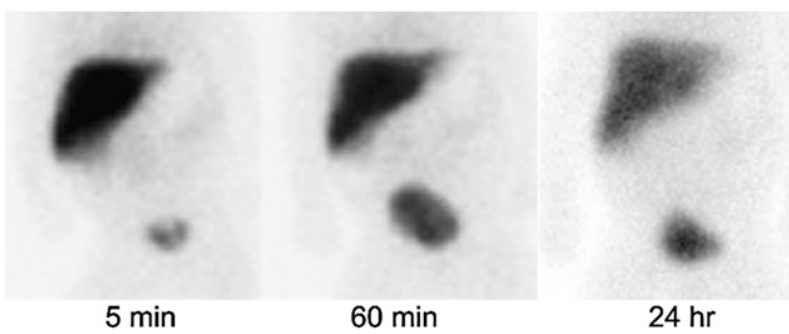

FIGURE 10. Hepatocellular disease and biliary atresia. (A) Newborn girl with hepatocellular disease. Selected images from ${ }^{99 m T c-}$ disofenin scintigraphy at 5,20 , and 60 min reveal tracer elimination into bowel (arrows). (B) One-week-old boy with biliary atresia. Selected images from 99mTc-disofenin scintigraphy at $5 \mathrm{~min}$, $60 \mathrm{~min}$, and $24 \mathrm{~h}$ do not show tracer in bowel. Large portion of tracer is eliminated by kidneys.

assessment of hepatocyte clearance and timing of radiotracer appearance in the intestine or extrahepatic biliary system for the evaluation of biliary atresia is helpful. In a normal study, radiotracer appears in the biliary tract or intestine within $15 \mathrm{~min}$ after injection. The scintigraphic diagnosis of biliary atresia is made when there is no intestinal activity through $24 \mathrm{~h}$ and hepatocyte uptake is high or relatively preserved. Studies are interpreted as compatible with hepatocellular damage when there is impaired hepatocyte uptake with a delayed hepatobiliary transit time, and radiotracer reaches the intestine (42).

\section{Gastric Emptying, Gastroesophageal Reflux, Aspiration, and Esophageal Transit}

Gastroesophageal reflux is common in babies. Some infants with gastroesophageal reflux present with respiratory symptoms including apnea, recurrent pneumonia, wheezing, recurrent stridor, and a chronic cough. Radionuclide assessment of gastric emptying is physiologic, noninvasive, and safe. Using a liquid meal, this method is useful both for assessment of gastric emptying and for diagnosis of gastroesophageal reflux. Radionuclide assessment of gastroesophageal reflux has advantages over conventional upper gastrointestinal series, as it is more sensitive, delivers a lower radiation exposure, monitors events continuously, does not involve administration of contrast agents, and does not require abdominal compressions.

In newborns and infants, gastric emptying is evaluated using milk or formula mixed with ${ }^{99 \mathrm{~m}} \mathrm{Tc}$-sulfur colloid. The patient should have been fasting for approximately $4 \mathrm{~h}$ before the study. Barium studies should not be obtained within $48 \mathrm{~h}$ before scintigraphy. The total volume of milk or formula to be administered should be approximately the same as the child usually takes in a regular meal. The tracer is mixed with approximately a third of the total expected volume to be administered, followed by the nonradioactive volume. Oral feeding is preferred, but depending on the patient's condition, labeled formula or milk can be administered by nasogastric or gastrostomy tube.

The patient is placed supine on the imaging table, and the $\gamma$-camera, equipped with a low-energy high-resolution collimator, is placed under the table. An initial image is used to determine the amount of tracer that has already left the stomach. Dynamic imaging is obtained for $60 \mathrm{~min}$ at 1 frame/min. Regions of interest are marked over the stomach, the esophagus, the rest of the abdomen, and the background, and time-activity curves, corrected for decay, are obtained. The gastric time-activity curve after placement of the child on the examining table provides another measure of gastric emptying time. Results are expressed as the percentage of the initial activity in the stomach (43-45). There are no widely accepted standards of normal gastric emptying times in this group. A study on healthy infants revealed a 1-h normal gastric residual of $48 \%-70 \%$. Another study showed that gastric emptying at $1 \mathrm{~h}$ in children younger than $2 \mathrm{y}$ was $27 \%-81 \%$. Gastric emptying time is affected by the position of the patient and other factors such as type and volume of food, patient anxiety, and pain. Children that show slow gastric emptying when supine can show rapid emptying by a simple change of position (45).

\section{Pulmonary Aspiration}

Pulmonary aspiration is a frequent cause of lung disease in children. Common imaging studies have traditionally included barium swallows, upper gastrointestinal series, and gastroesophageal scintigraphy, but these approaches have shown low diagnostic yield for aspiration. The infrequent demonstration of aspiration with radionuclide gastroesophageal studies suggests that aspiration of gastric contents is not a common mechanism of recurrent pulmonary infections in children.

The radionuclide salivagram has proven to be a sensitive and simple method for detecting pulmonary aspiration of oral contents (46-48). No patient preparation is required for the salivagram. A single drop of saline containing 3.7-7.4 MBq $(0.100-0.200 \mathrm{mCi})$ of ${ }^{99 \mathrm{~m}} \mathrm{Tc}$-sulfur colloid is delivered sublingually. Typically, the patient is imaged for $60 \mathrm{~min}$ at 1 frame/min in the supine position with a $\gamma$-camera viewing the posterior aspect of the head, thorax, and abdomen. It is important to identify any contamination of tracer outside the patient's body that could be confused with aspiration.

Images are inspected for tracer aspiration into the proximal or distal airways (Fig. 11). Tracer deposited in the proximal airways tends to be cleared rapidly by the mucociliary epithelium, whereas tracer reaching the distal airways (where there is less ciliary epithelium) persists longer. By assessing the ability to clear aspirated secretions, the radionuclide salivagram evaluates the functional integ- 


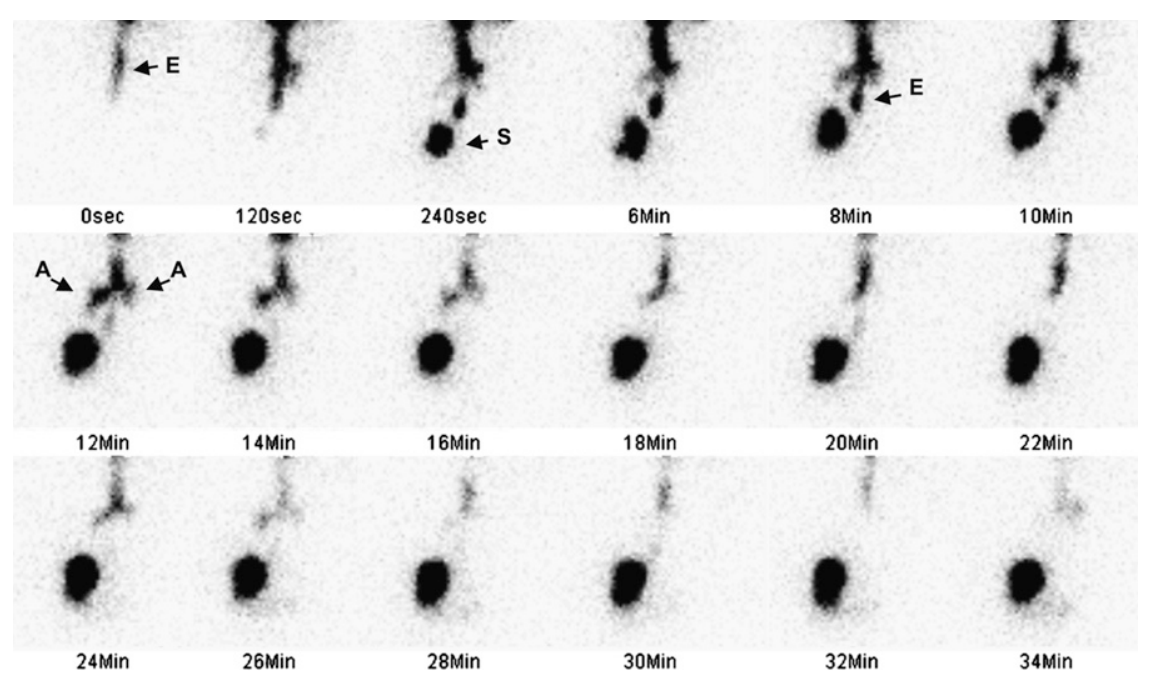

FIGURE 11. Aspiration and salivagram. In 18-d-old boy, tracer mixed with patient's saliva migrates down esophagus $(E)$ into stomach (S). Aspirated activity in mainstem bronchi is seen from $120 \mathrm{~s}$ to $16 \mathrm{~min}$ (arrows, A). By 18-20 min, aspirated secretions have cleared. At 24 min, tracer is aspirated again but is cleared again. rity of airway-protective mechanisms. Aspiration into the distal airways suggests a more worrisome outcome than proximal aspiration. The whole-body radiation dose to the patient is approximately $0.05 \mathrm{mSv}$ (5 mrem), whereas barium swallow delivers a higher radiation dose (46-48).

\section{Gastrointestinal Bleeding}

The most common cause of lower gastrointestinal bleeding in previously healthy infants is from a Meckel's diverticulum. This is a congenital abnormality of the antimesenteric duct that is the result of incomplete closure of the embryonic vitelline or omphalomesenteric duct. Bleeding from a Meckel's diverticulum is a result of peptic ulceration of ileal mucosa either in the diverticulum or in the adjacent ileum. The typical presentation of a bleeding Meckel's diverticulum is painless rectal bleeding of bright red blood. Most infants presenting with bright red bleeding from a Meckel's diverticulum contain functioning ectopic gastric mucosa (49-52).

Premedication with perchlorate should be avoided because it suppresses tracer uptake in gastric mucosa. Scintigraphy is performed with ${ }^{99 \mathrm{~m}} \mathrm{Tc}$-pertechnetate injected intravenously (9.25 MBq [0.25 mCi]). The patient lies supine with the $\gamma$-camera viewing the lower thorax, abdomen, and pelvis. If indicated, a radionuclide angiogram should be obtained to evaluate for vascular malformations. Recording is set at 1 - to 5 -s frames for $60 \mathrm{~s}$, followed immediately with a series of 1-min images for $30 \mathrm{~min}$ (52).

The scintigraphic appearance of a Meckel's diverticulum is typical. A well-defined area of increased radiopertechnetate uptake, usually in the right lower quadrant, is seen. This area can move and be located anywhere in the abdomen. Pertechnetate uptake in the ectopic gastric mucosa appears at the same time as activity in the stomach and shows increasing intensity over time. Lateral and posterior images are helpful to differentiate this activity from tracer within the ureters and the bladder. Because a Meckel's diverticulum could lie near the urinary bladder, preventing detection, obtaining other views or ensuring that the blad- der is empty helps detection (50). If the initial 30-min study appears normal in newborns or young infants and a Meckel's diverticulum is strongly suspected, the physician may consider obtaining additional images 1-2 $\mathrm{h}$ later to achieve higher lesion-to-background ratios. If the index of suspicion is high, a scan repeated a few months later may reveal functioning ectopic mucosa.

The accuracy of pertechnetate for the diagnosis of Meckel's diverticulum in surgical patients is $90 \%$, the overall sensitivity is $85 \%$, and the specificity is $95 \%$ (51). Enteric duplication, duplication cysts, and gastrogenic cysts are other abnormalities that may contain ectopic gastric mucosa. Other conditions, not containing gastric mucosa, that may accumulate pertechnetate include intestinal obstruction or intussusception, inflammation, vascular malformations, ulcers, some tumors, and various urinary tract abnormalities, but these are usually easy to recognize (52).

\section{Spleen}

Splenic scintigraphy using ${ }^{99 \mathrm{~m}} \mathrm{Tc}$-heat-damaged red blood cells is an effective method in the diagnosis of functional asplenia or polysplenia in these small patients (53).

\section{Kidneys}

Radionuclide evaluation of renal function is one the most frequent indications in children during the first year of life. Clinical applications of these methods include obstruction, postoperative assessment, pyelonephritis, duplication, ectopic kidney or nonvisualization of a kidney, renal vein thrombosis, acute renal failure, multicystic dysplastic kidney, reflux, trauma, transplant, and tumors (abdominal or renal) (54). The 2 principal radiopharmaceuticals used in this group of patients are ${ }^{99 \mathrm{~m}} \mathrm{Tc}-\mathrm{MAG} 3$ to evaluate tubular function, split renal function, and collecting system drainage and ${ }^{99 \mathrm{~m} T c-}$ DMSA to image the renal cortex to assess split renal function and cortical defects.

${ }^{99 m}$ Tc-MAG3 is the agent of choice for dynamic renal scintigraphy and can effectively evaluate renal function and urine drainage. After intravenous injection, ${ }^{99 \mathrm{~m}} \mathrm{Tc}-\mathrm{MAG} 3$ is 
eliminated rapidly by the kidneys, mainly by active tubular cell transport. The plasma clearance of this tracer is approximately $300 \mathrm{~mL} / \mathrm{min}$, and after $3 \mathrm{~h}$ approximately $90 \%$ of the injected dose can be recovered in urine. ${ }^{99 \mathrm{~m}} \mathrm{Tc}-\mathrm{MAG} 3$ has a high initial renal uptake and provides a high kidneyto-background ratio and high temporal resolution. An intravenous line is secured and connected to a saline infusion at $10 \mathrm{~mL} / \mathrm{kg}$, which is maintained throughout the study. A bladder catheter is inserted if urinary tract obstruction is suspected in patients with vesicoureteric reflux, ureteropelvic obstruction, or ureterovesical obstruction or in young patients who may not be able to void on command. The $\gamma$-camera, equipped with a parallel-hole high- or ultra-highresolution collimator is placed under the examination table viewing the kidneys and the bladder. The usual administered dose of ${ }^{99 \mathrm{mTc}-M A G 3}$ is $3.7 \mathrm{MBq}(0.1 \mathrm{mCi}) / \mathrm{kg}$ in approximately $0.1 \mathrm{~mL}$ given intravenously. The study is recorded for $20 \mathrm{~min}$ at $1-4$ frames $/ \mathrm{min}$ on a $128 \times 128$ matrix format. If, at the end of the 20-min acquisition period, spontaneous urine drainage from the pelvicalyceal system is not seen, the infant is picked up and held upright for a few minutes to promote drainage. Then, a static image is obtained and is compared with the previous images to determine postural drainage. If drainage is adequate, the study is ended. If the image still shows tracer retained in the pelvicalyceal system, a diuretic challenge may be considered. Furosemide $(1 \mathrm{mg} / \mathrm{kg})$ is administered intravenously while an additional 30 -min dynamic study is recorded at 1-4 frames/min. The study is typically viewed at $1 \mathrm{frame} / \mathrm{min}$, and time-activity curves are generated from regions over the kidneys (whole kidney, cortex) and background. A normal dynamic renal study reveals rapid and intense tracer concentration in the renal cortex at approximately 2 min after injection. Passage of the tracer into the renal pelvicalyceal system normally occurs at $2-4 \mathrm{~min}$. The parenchymal phase (60-120 s) provides information about total renal function, relative renal size, position, configuration, and split renal function. The parenchymal image can reveal hydronephrosis, a duplex kidney, or other relatively large anatomic abnormalities. During the drainage phase, the tracer is gradually eliminated into the bladder through the pelvicalyceal system and ureters. By $20 \mathrm{~min}$, a large proportion of the tracer has left the kidneys and less than $30 \%$ of the peak activity may remain in the renal region. If the patient moved during the study, motion correction is applied. Images and time-activity curves are also generated after the administration of furosemide. These curves are evaluated to determine whether there is obstruction, intermediate drainage, or no obstruction (Figs. 12 and 13).

During the first months of life, renal immaturity affects the handling of ${ }^{99 \mathrm{~m} T c-M A G 3}$, and interpretation of studies must take this factor into account. Immature kidneys show relatively low uptake of ${ }^{99 \mathrm{~m}} \mathrm{Tc}-\mathrm{MAG} 3$ and slower cortical transit times, with prolonged time to peak and increased residual tracer at $20 \mathrm{~min}$. As renal maturation takes place, function matures and handling of ${ }^{99 \mathrm{~m}} \mathrm{Tc}-\mathrm{MAG} 3$ approaches adult levels. In renal immaturity, ${ }^{99 m}$ Tc-MAG3 studies may over- or underestimate the true contribution of a hydronephrotic kidney to total renal function. In these cases, a 99mTc-DMSA scan provides a better assessment of differential renal parenchymal function.

${ }^{99 \mathrm{~m} T c-D M S A}$ is the radiopharmaceutical of choice for renal cortical scintigraphy. It is $90 \%$ bound to plasma proteins, and $0 \%-5 \%$ is bound to red cells. Its blood disappearance follows a single exponential with a mean half-time of $60 \mathrm{~min}$, and 6\%-9\% of the dose is present in the blood at 14 $\mathrm{h}$ after injection. Renal uptake of ${ }^{99 \mathrm{~m} T c-D M S A}$ is $40 \%-$ $50 \%$ of the injected activity at 3-4 h after injection. Activity is found principally in the proximal convoluted tubules, with minimal activity elsewhere in the kidney. Renal uptake of ${ }^{99 \mathrm{~m}} \mathrm{Tc}-\mathrm{DMSA}$ is closely correlated with regional renal blood flow and renal mass (55-57). ${ }^{99 \mathrm{~m}} \mathrm{Tc}-\mathrm{DMSA}$ is administered intravenously $3-4 \mathrm{~h}$ before imaging. The usual administered dose is $1.85 \mathrm{MBq}(0.05 \mathrm{mCi}) / \mathrm{kg}$. In children younger than $1 \mathrm{y}$, planar and pinhole images are obtained. The planar images are useful for evaluating the position and overall configuration of the kidneys and for calculating split renal function. The pinhole images provide higher resolu-
FIGURE 12. Renal immaturity, left obstruction, and effect of pyeloplasty. Preand postoperative 99mTc-MAG3 studies from 8-mo-old girl with preoperative diagnosis of left hydronephrosis. (A) Preoperative study shows dilatation of left kidney with reduced function $(37 \%)$ and drainage before and after furosemide, indicating obstruction. Also, note immaturity of right kidney with prolonged transit time and high residual activity at $20 \mathrm{~min}$ after tracer administration. (B) Since pyeloplasty 5 mo earlier, left kidney regained function (now $49 \%$ ), and postfurosemide half-time (T1/2) washout is $2.4 \mathrm{~min}$. Right kidney has matured, and right time-activity curve shows earlier peak and normal rapid washout before furosemide.

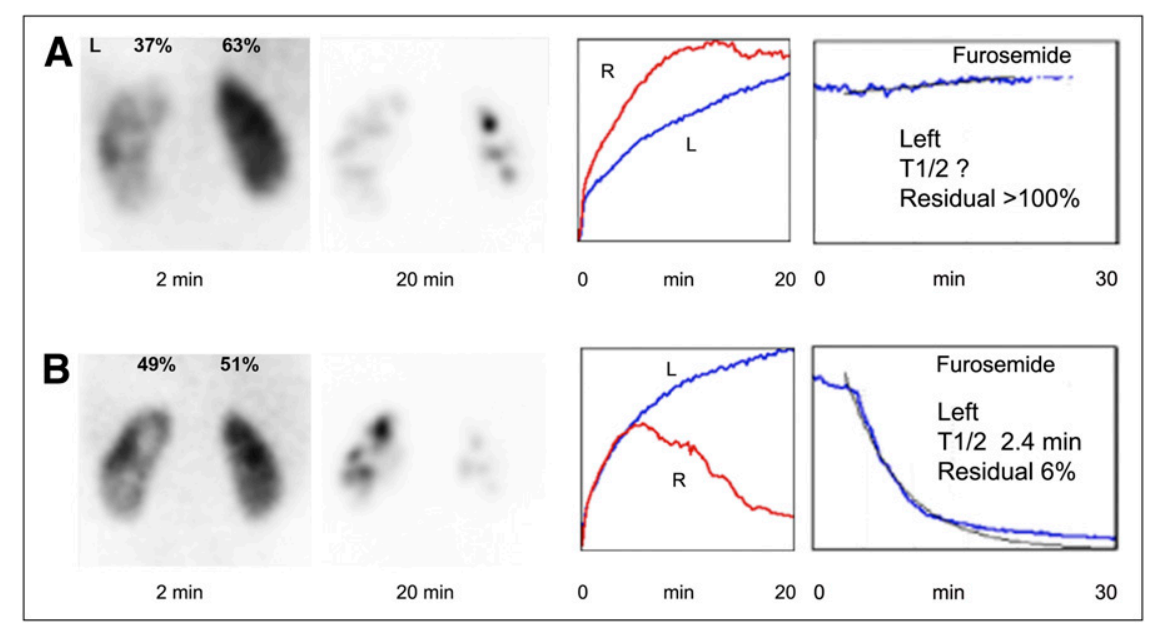




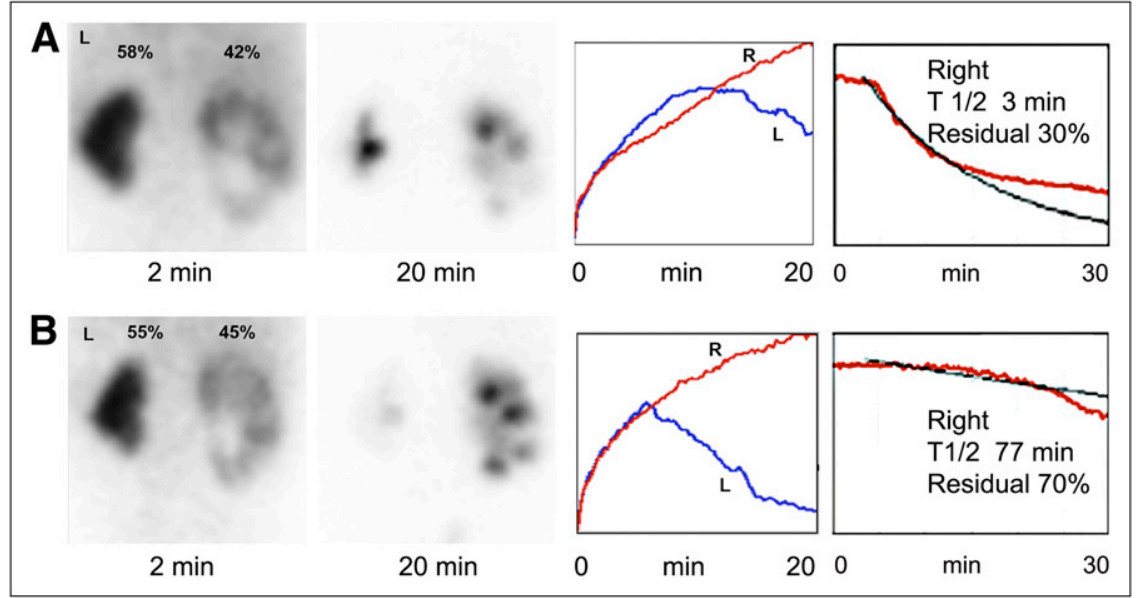

FIGURE 13. Immaturity, maturation, and worsening. $99 \mathrm{mTC}-\mathrm{MAG} 3$ studies from 9mo-old girl taken 6 mo apart, with no surgery performed between examinations. (A) Right kidney is hydronephrotic and shows no evidence of spontaneous drainage during first $20 \mathrm{~min}$. After furosemide administration, washout half-time (T1/2) is $3 \mathrm{~min}$, but with residual activity of $30 \%$. Time to peak is long, and transit of tracer in right kidney is slow. (B) Six months later, hydronephrotic right kidney continues to show no evidence of spontaneous drainage. After furosemide, half-time washout is quite prolonged, with residual activity of $70 \%$. Left kidney shows signs of maturation. Time to peak is close to normal, and drainage is normal. tion to detect focal cortical defects. The patient is examined supine, and a posterior image containing 300,000-500,000 counts on a $256 \times 256$ matrix is recorded using a highresolution or an ultra-high-resolution collimator. Posterior images with the patient prone are obtained with the pinhole collimator (2- to 4-mm aperture), which provides resolution of approximately $2-3 \mathrm{~mm}$. Cortical defects in pyelonephritis, infarction, scarring, duplication, and fetal lobations can be discerned better with pinhole magnification than with parallel-hole collimators. Each pinhole image is obtained for approximately 150,000 counts in a $256 \times 256$ matrix and requires approximately $10 \mathrm{~min}$. The normal differential renal uptake of ${ }^{99 \mathrm{~m} T c-D M S A}$ is $50 \% \pm 5 \%$ (54). A small amount of ${ }^{99 \mathrm{~m}} \mathrm{Tc}-\mathrm{DMSA}$ is eliminated in the urine, and in children with hydronephrosis unrecognized pooling of tracer in the pelvicalyceal system could lead to a misleading assessment of differential renal function. In these cases, an image obtained 12-24 h after tracer administration, allowing for a more complete drainage of retained tracer, should permit a better estimate of differential renal function. Also, a ${ }^{99 \mathrm{~m}} \mathrm{Tc}-\mathrm{DMSA}$ image is useful when ${ }^{99 \mathrm{~m}} \mathrm{Tc}-$ MAG3 does not reveal much renal function.

After prenatal diagnosis of hydronephrosis, there are important clinical questions that should be answered so that appropriate treatment can be instituted. These questions include how much function the hydronephrotic kidney has, whether renal obstruction is present, and whether the problem is unilateral or bilateral. ${ }^{99 \mathrm{~m}} \mathrm{Tc}-\mathrm{MAG} 3$ renography can help answer these questions rapidly and efficiently. Early ${ }^{99 m}$ Tc-MAG3 studies on the newborn or infant with hydronephrosis may reveal obstruction, an intermediate pattern, or a dilatation of the pelvicalyceal system without obstruction. Early findings are not generally predictive of the ultimate outcome but are considered a useful snapshot in time during renal maturation (54-56,58-64). If immediate surgical intervention is not indicated after the initial study, reassessment in 3-6 mo should be considered. Subsequent studies may indicate spontaneous resolution or progression of the disorder. Patients with hydronephrosis and normal or nearly normal cortical transit times have a high likelihood of recovery of renal function postoperatively, whereas prolonged cortical transit times are associated with a poorer prognosis for functional improvement. Postoperative dynamic renal studies are useful for patients who have undergone pyeloplasty or another intervention for the relief of obstruction. Postoperative studies should be performed approximately $2 \mathrm{wk}$ after surgery to reduce the effects of postoperative swelling and edema. Postoperative ${ }^{99 \mathrm{~m} T c-}$ MAG3 studies may reveal a reduction in the size of the previously hydronephrotic kidney with return to more normal function. However, the dilated system may not be completely resolved. Although postoperative ${ }^{99 \mathrm{~m} T c-}$ MAG3 studies may show residual obstruction, a diuretic challenge may help separate those patients in whom the surgery successfully relieved the obstruction from those with residual obstruction.

If prenatal ultrasonography demonstrates a single or solitary kidney, a ${ }^{99 \mathrm{~m}} \mathrm{Tc}-\mathrm{DMSA}$ scan can be useful in confirming the presence of a solitary kidney or in identifying a previously undetected ectopic kidney.

Pyelonephritis in young children may present with symptoms that vary and can be confusing. Differentiation of upper from lower urinary tract infection on clinical grounds alone is not easy. Neonates and infants, in particular, present with nonspecific clinical findings such as fever, abdominal pain or tenderness, malaise, irritability, or leukocytosis with or without bacteriuria, but there may be no indication of renal infection. ${ }^{99 \mathrm{~m}} \mathrm{Tc}-\mathrm{DMSA}$ scintigraphy is the most reliable, simplest, and most sensitive method for the early diagnosis of focal or diffuse functional cortical damage. This test can identify the degree of renal damage and assess recovery of function after treatment. The high sensitivity of ${ }^{99 \mathrm{~m}} \mathrm{Tc}-$ DMSA scintigraphy for the diagnosis of pyelonephritis is well established. Sensitivity is $96 \%$, and specificity is better than $98 \%$ (62-64).

Renal duplication can be detected by ${ }^{99 \mathrm{~m} T c-D M S A}$ scintigraphy. Duplication may not easily be seen with highresolution collimators, but pinhole magnification can 
clearly reveal this abnormality and evaluate function of the different moieties.

Multicystic dysplasia of the kidney is the most frequent cystic disorder of infants. In approximately $75 \%$ of the cases, ${ }^{99 m}$ Tc-DMSA scintigraphy does not demonstrate tracer uptake in the involved kidney. However, in some instances some variable tracer uptake can be seen in regions of distorted renal cortex. Often this uptake can be demonstrated only with computer enhancement. The scintigraphic appearance of multicystic dysplasia of the kidney can occasionally be similar to neonatal hydronephrosis.

In anuric newborns during the first day of life, radionuclide studies can demonstrate the presence of functional renal units even before the baby is able to urinate.

\section{Vesicoureteral Reflux (VUR)}

VUR is due to a failure of the ureterovesical valve mechanism caused by a congenital variation, a pathologic process, an infection, or immaturity that distorts the anatomy or function (or both) of the ureterovesical junction. The incidence of VUR in apparently healthy neonates and infants is approximately $1 \%$. The diagnosis, follow-up, and treatment of VUR is based on the premise that in children with a history of urinary tract infection, persistent and untreated VUR may lead to renal damage. Most VUR tends to disappear with maturation. Spontaneous cessation of reflux occurs in approximately $70 \%$ of children and $79 \%$ of ureters. Spontaneous resolution of reflux is more frequent with lowgrade reflux and is less frequent with high grades of reflux, although spontaneous resolution can occur even with high grades of reflux $(65,66)$. Radionuclide cystography (RNC) can be used effectively in children younger than 1 y (67).

The indications for RNC in children less than $1 \mathrm{y}$ old include the following: an initial diagnosis of reflux in patients with signs and symptoms of urinary tract infection, follow-up of an earlier diagnosis of reflux to assess spontaneous cessation, diagnosis of familial reflux, and postoperative assessment of antireflux surgery.

RNC is sensitive, because it provides continuous monitoring both during filling of the bladder and during voiding and has a high contrast, enabling detection of reflux as slight as $0.2 \mathrm{~mL}(68,69)$. There is no need for patient preparation or sedation. Sterile urethral catheterization trays containing all needed materials are prepared for each study in advance. The patient is positioned supine on the examination table, which is covered with absorbent plastic-lined material to collect any contamination. After appropriate cleansing of the perineum and genitals with antiseptic solution, a small-diameter catheter covered with anesthetic jelly is introduced into the patient's bladder. Careful and gentle catheterization technique by experienced personnel is essential to ensure consistently successful studies. ${ }^{99 \mathrm{~m} T c-}$ pertechnetate $(37 \mathrm{MBq}[1 \mathrm{mCi}])$ is introduced into the bladder, followed by a saline infusion with the saline bag kept 70-90 $\mathrm{cm}$ above the bladder. Serial posterior images are obtained with the $\gamma$-camera $(0.25$-s frames at a $128 \times$
128 matrix) until the patient's functional bladder capacity is reached and the patient is able to void either around the catheter or immediately after catheter removal (69). If the patient cannot void or does not void after complete bladder filling, a postvoid image is obtained. This step is important because approximately $20 \%$ of reflux is detected only during voiding. Residual bladder volume, voided volume, bladder capacity, and any problems during the catheterization should be documented.

Reflux can be detected during one or all phases: early, mid, or late filling; voiding; and after voiding. The international classification of reflux by vesicoureterogram includes 5 grades (I-V) of severity (65). RNC classification includes $3^{\circ}$ of increasing severity: RNC grade 1 refers to reflux within the distal ureter only and not reaching the renal pelvis (equivalent to vesicoureterogram grade I). Typically, $0.2 \mathrm{~mL}$ of reflux that projects at least $2 \mathrm{~cm}$ away from the projected border of the bladder can be detected. RNC grade 2 refers to reflux that reaches the renal pelvis, without pelvic dilatation and without a dilated or redundant ureter (equivalent to vesicoureterogram grades II and III). RNC grade 3, the most severe, shows reflux into the renal pelvis with significant dilatation of the pelvis or tortuosity of the ureter (equivalent to vesicoureterogram grades IV and V) (68).

Approximately two thirds of all VUR resolves spontaneously as a result of growth and maturation. Low-grade VUR varies from examination to examination. VUR varies also with bladder volume, voiding or filling, patient position, and level of anxiety. Thus, a single normal examination may not be sufficient to ensure that reflux has ceased. Serial cystograms over several (6-12) months can be more reassuring, and in the small number of patients with apparently resolved VUR, another urinary infection may be an indication for a repeated RNC.

The incidence of VUR in siblings of children with reflux is approximately $40 \%$. We have found that reflux severity in these asymptomatic children varies widely from mild to severe (68-70). The incidence of renal cortical damage in these siblings with VUR is high $(68,71-74)$. Thus, when VUR is diagnosed in a child, evaluation for VUR is appropriate in the siblings $(74,75)$.

Radiation exposure in children undergoing RNC was estimated at $0.18 \mathrm{mGy}(18 \mathrm{mrad})$ to the bladder wall and at $0.01 \mathrm{mGy}(1 \mathrm{mrad})$ to the ovaries. The testicular dose is lower than the dose to the ovaries. The dose to the ovaries is much less with RNC than with a conventional vesicoureterogram, even with the use of pulsed fluoroscopy.

\section{Bone}

Indications for skeletal scintigraphy in children under $1 \mathrm{y}$ old include osteomyelitis, trauma, avascular necrosis, Langerhans cell histiocytosis, fever of unknown origin, and neoplastic disease (76). Skeletal planar scintigraphy and SPECT with ${ }^{99 m}$ Tc-MDP, as well as ${ }^{18} \mathrm{~F}-\mathrm{NaF}$ PET, are useful imaging tools. The usual administered dose of ${ }^{99 \mathrm{~m}} \mathrm{Tc}-\mathrm{MDP}$ is 
$37 \mathrm{MBq}(1 \mathrm{mCi})$. The usual ${ }^{18} \mathrm{~F}-\mathrm{NaF}$ PET dose is $18.5 \mathrm{MBq}$ $(0.5 \mathrm{mCi})$. PET is acquired $15-30 \mathrm{~min}$ after the intravenous injection. The effective dose for ${ }^{18} \mathrm{~F}-\mathrm{NaF}$ PET for a $1-\mathrm{y}$-old patient is estimated at $3.1 \mathrm{mSv}$ (310 mrem) (77).

Image interpretation in infants requires special attention due to the differences in radiopharmaceutical biodistribution between immature children and adults. In infants, an important consideration is the absence of ${ }^{99 \mathrm{~m}} \mathrm{Tc}-\mathrm{MDP}$ or ${ }^{18} \mathrm{~F}-\mathrm{NaF}$ uptake in structures that have not yet ossified. For example, the femoral capital epiphysis ossifies between the ages of 2 and $7 \mathrm{mo}$, and absence of uptake should not be confused with avascular necrosis. The tarsal navicular bone usually ossifies after the age of $1 \mathrm{y}$, and radiotracer uptake is absent in infants. The cartilaginous junction between the inferior pubic ramus and the ischium (ischiopubic synchondrosis) ossifies after the age of $4 \mathrm{y}$. Therefore, in infants, there is physiologic discontinuity of the inferior pubic ramus. In contrast, there is high radiotracer uptake in the physeal growth centers of long bones and the apophyseal growth centers of flat and irregular bones. Infants have physiologically increased uptake in the apophyses at the inferior tip of the scapula and the vertebral transverse process. Normally, there is high tracer uptake in the skull base, orbits, nasal region, temporomandibular joints, and cranial sutures, whereas absence of uptake may be seen in the region of the anterior fontanelle. As growth centers close, the biodistribution of ${ }^{99 \mathrm{~m}} \mathrm{Tc}-\mathrm{MDP}$ gradually reaches the adult pattern (76-84). One special indication in this age group is evaluation for skeletal injury in suspected cases of child abuse (85).

\section{Infection and Inflammation}

Infection is a common indication for skeletal scintigraphy in infants. Early diagnosis and treatment of osteomyelitis is important to avoid complications such as sepsis, growth arrest, and skeletal injury. Skeletal scintigraphy is a reliable tool for the diagnosis of osteomyelitis even in the youngest patients (79). Three-phase skeletal scintigraphy can demonstrate abnormalities within 24-72 h of symptom onset and is both sensitive and specific for osteomyelitis (Fig. 14) (76). Whole-body imaging is helpful because symptoms may not be localized and findings may be multifocal. Diagnostic aspiration and antibiotic treatment do not need to be delayed, because the appearance on scintigraphy does not change rapidly. Photopenic defects may indicate regional ischemia.

Septic arthritis or inflammation of a joint typically involves the hip or knee in children less than 3 y old. Timely diagnosis is important to avoid complications. Skeletal-phase images may be normal or demonstrate mildly increased juxtaarticular uptake. Reduced tracer uptake may occasionally be seen, such as in the presence of a tense joint effusion. In cellulitis, skeletal scintigraphy reveals increased regional blood flow and increased tracer accumulation in the soft tissue in the region involved and a normal or slightly and diffusely increased tracer concentration in the adjoining bones (Fig. 15).

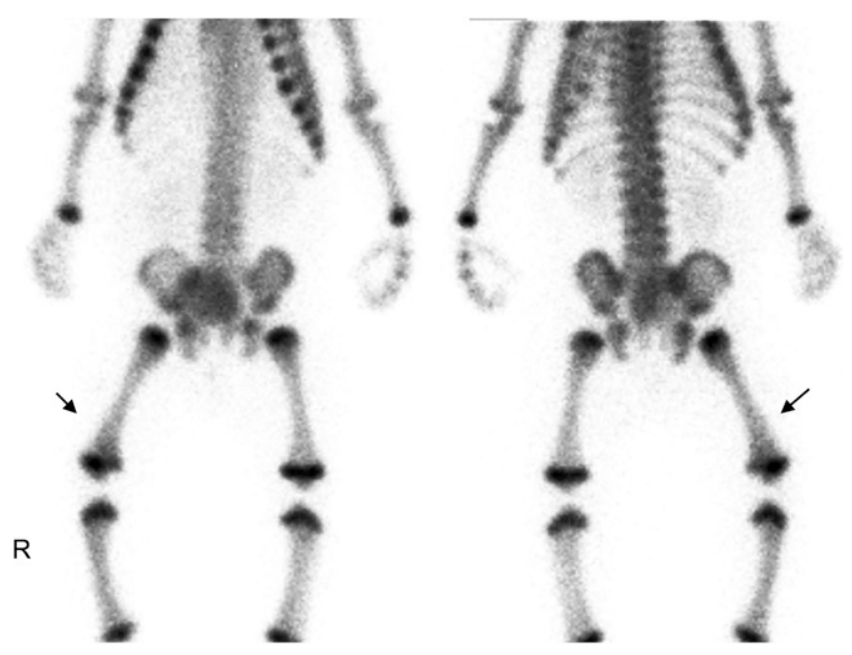

FIGURE 14. Osteomyelitis. In 6-mo-old boy with osteomyelitis of right femur (arrows), tracer uptake is increased along entire femur, with greater intensity in right distal femur.

\section{Fever of Unknown Origin}

The term fever of unknown origin is defined as recurrent fever of $101^{\circ} \mathrm{F}\left(38.3^{\circ} \mathrm{C}\right)$ or higher, lasting $2-3$ wk or longer with no specific diagnosis after $1 \mathrm{wk}$ of inpatient investigation. The differential diagnosis of fever of unknown origin in infants is broad and includes infection, connective tissue disease, and neoplasm. Skeletal scintigraphy is a sensitive tool for the detection of osseous disease and is often requested in the evaluation of infants with fever of unknown origin. However, in our experience, skeletal scintigraphy usually adds little diagnostic information, without localizing findings, in the assessment of infants presenting to the emergency department with fever.

If skeletal scintigraphy is performed, the physician should pay close attention to subtle soft-tissue uptake, which may identify the location of an occult inflammatory or neoplastic process. ${ }^{18} \mathrm{~F}-\mathrm{FDG}$ PET has the potential to identify soft-tissue lesions (inflammation, tumors).

\section{Trauma and Nonaccidental Injury}

In infants with suspected trauma, the history of injury is not always available and clinical localizing findings may not be present. Furthermore, trauma from suspected nonaccidental injury often results in multiple skeletal fractures at different stages of healing. Skeletal scintigraphy offers a highly sensitive imaging tool for evaluation of the entire skeleton (84). Osseous stress or fracture may be identified on skeletal scintigraphy by increased radiotracer uptake within a few hours of symptom onset and before radiographic changes appear $(80,81)$. Although MRI is sensitive for the detection of osseous disease and does not expose the infant to ionizing radiation, it has a limited field of view and usually requires sedation. Skeletal trauma and fractures are a common presentation in infants suspected of child abuse. The detection of all fractures is essential in this clinical setting because the discovery of new fractures has the potential to alter the medicolegal 


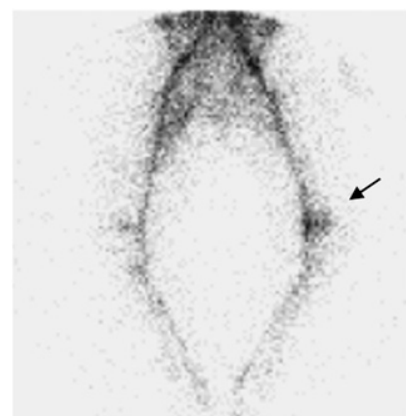

A

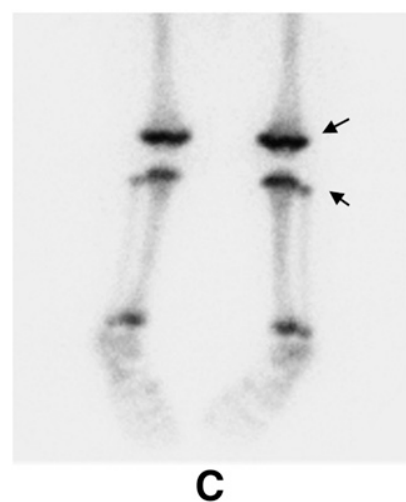

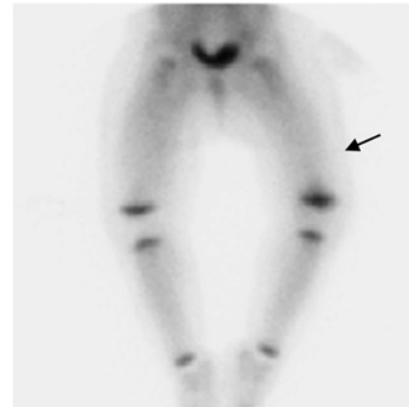

B

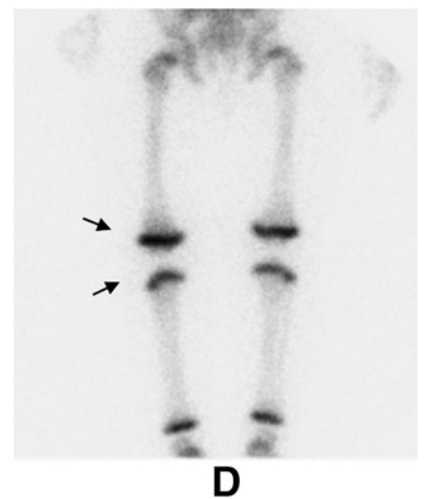

FIGURE 15. Cellulitis. In 5-mo-old girl, 99mTc-MDP radionuclide angiogram (A) shows increased tracer delivery (arrow) in soft tissue in region of left distal femur, tissue-phase image (B) shows diffusely increased tracer accumulation (arrow) in region surrounding left distal femur and in region of growth plate, and skeletal-phase images $(C$ and $D)$ show minimal increased tracer uptake (arrows) in growth centers of distal femur and proximal tibia.

management of the patient. Skeletal scintigraphy is established as a study complementary to the radiographic skeletal survey, and some authors have recommended that both studies be done $(82,83)$. The sensitivity of standard ${ }^{99 \mathrm{~m}} \mathrm{Tc}$-MDP skeletal scintigraphy for the detection of fractures varies greatly depending on the location of the lesion (Fig. 16) $(78,83)$.

${ }^{18} \mathrm{~F}-\mathrm{NaF}$ PET has recently been proposed as an alternative to ${ }^{99 \mathrm{~m} T c-M D P}$ in the evaluation of child abuse. ${ }^{18} \mathrm{~F}$ $\mathrm{NaF}$ has less protein binding in blood than ${ }^{99 \mathrm{~m} T c-M D P}$, allowing imaging at about $15 \mathrm{~min}$ after administration $(77,85)$. Both ${ }^{99 \mathrm{~m} T c-M D P}$ and ${ }^{18} \mathrm{~F}-\mathrm{NaF}$ PET are effective in child abuse and show an overall higher sensitivity than an initial radiographic skeletal survey. ${ }^{18} \mathrm{~F}-\mathrm{NaF}$ PET was found to have a sensitivity of $92 \%$ for the detection of rib fractures, versus $68 \%$ by skeletal survey (85). Comparative studies of the relative sensitivity and specificity of ${ }^{99 \mathrm{~m}} \mathrm{Tc}-$ MDP, planar imaging, SPECT, and ${ }^{18} \mathrm{~F}-\mathrm{NaF}$ PET in children less than 1 y old are not available.

\section{Oncology}

Oncologic disorders of infancy account for approximately $10 \%$ of all cancer diagnoses in children younger than $15 \mathrm{y}$ (86). It is estimated that the peak age for pediatric cancer is the first year of life. Neuroblastoma is the most commonly diagnosed tumor in this age range, followed by leukemia and
A
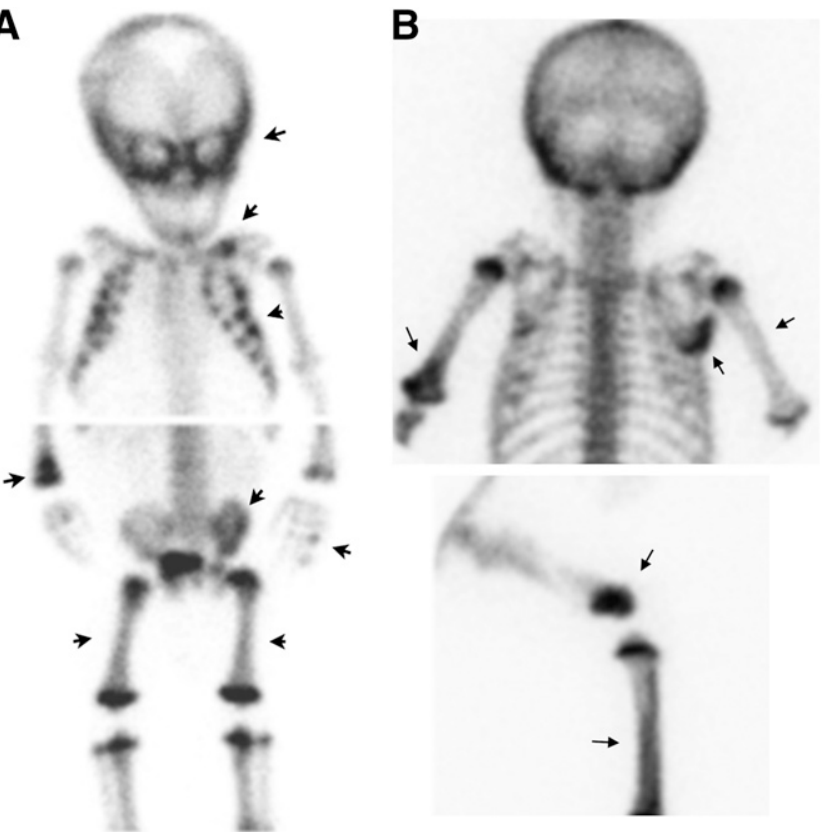

FIGURE 16. Nonaccidental trauma. (A) On 99mTc-MDP scan of 2.5-mo-old boy, skeletal injuries from child abuse are seen. Multiple regions of increased tracer uptake (arrows) are seen in left skull, left clavicle, several ribs bilaterally, right distal radius and ulna, some phalanges of both hands, left iliac bone, femurs, and left tibia. (B) On 99mTc-MDP scan of 3.5-mo-old girl, multiple regions of increased uptake (arrows) are seen in both humeri, right scapula, right distal femur, and right tibia.

brain tumors, germ cell tumors, and other soft-tissue tumors (Fig. 17) (87). Nuclear medicine is an effective way to diagnose, stage, and survey cancer in infants (88). The radiopharmaceuticals used for planar oncologic scintigraphy include ${ }^{99} \mathrm{~m}$ Tc-MDP, ${ }^{123} \mathrm{I}-\mathrm{MIBG}$, and ${ }^{99 \mathrm{~m} T c-M I B I}$. SPECT provides increased contrast, and newer reconstruction methods provide improved spatial resolution (10-12). Furthermore, SPECT may be fused with MRI or CT for anatomic localization. ${ }^{18} \mathrm{~F}$-FDG PET is increasingly being used in pediatric oncology, although the exact role of PET in infants has not yet been established.

\section{Neuroblastoma}

Neuroblastoma, ganglioneuroblastoma, and ganglioneuroma are tumors of the sympathetic nervous system. These tumors arise from the neural crest cells that form the sympathetic tissue. Neuroblastoma is the most frequently diagnosed malignancy within the first few months of life. Neuroblastoma most commonly involves the adrenal glands, or it may be associated with sympathetic nerves in the cervical, posterior mediastinal, retroperitoneal, and presacral regions. Less common sites of disease include the thymus, lung, kidney, anterior mediastinum, stomach, and cauda equina (88). Disseminated disease is seen in approximately $70 \%$ of neuroblastoma cases at diagnosis (89).

${ }^{123} \mathrm{I}-\mathrm{MIBG}$ and ${ }^{99 \mathrm{~m}} \mathrm{Tc}-\mathrm{MDP}$ skeletal scintigraphy play a key role in the diagnosis, staging, and follow-up evaluation of infants with neuroblastoma $(90,91) .{ }^{123}$ I-MIBG scintig- 


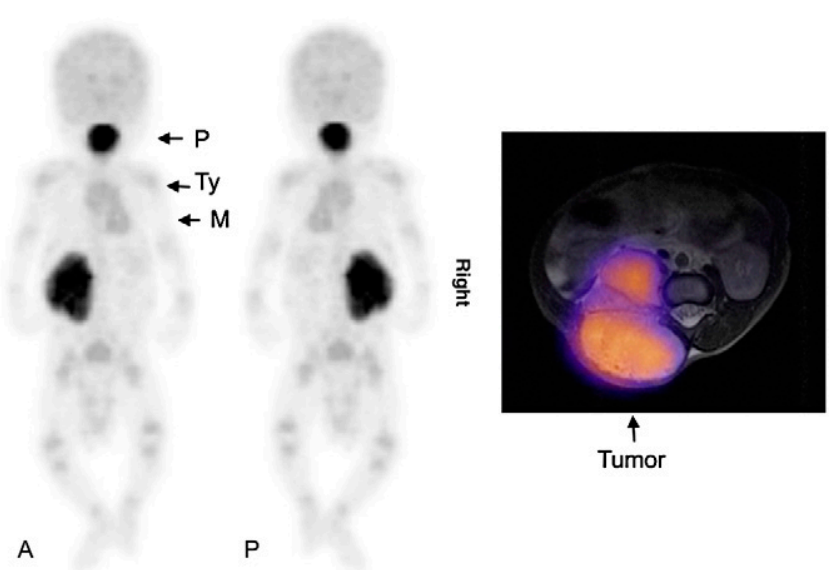

FIGURE 17. Neuroblastoma. In 1-y-old girl with opsoclonusmyoclonus and abnormal eye movements, MRI revealed right adrenal mass. ${ }^{123}$ I-MIBG fused to MRI reveals tracer uptake within lesion. Tracer uptake in region of mouth and face was thought to be due to baby vigorously sucking his pacifier $(P)$ during uptake period and during scan. Thymic (Ty) and myocardial (M) uptake are seen.

raphy and SPECT are both sensitive and specific for the detection of primary and metastatic neuroblastoma. ${ }^{123} \mathrm{I}-$ MIBG is highly specific in the diagnosis of neuroendocrine tumors. Physiologic ${ }^{123}$ I-MIBG uptake can include the salivary glands, myocardium, liver, spleen, adrenal glands, skeletal muscle, brown adipose tissue, bladder, and colon (91,92).

Although most neuroblastoma tumors are ${ }^{123} \mathrm{I}-\mathrm{MIBG}-$ positive, a normal ${ }^{123}$ I-MIBG scintigraphy result does not completely exclude malignancy. ${ }^{99 \mathrm{~m} T \mathrm{Tc}-\mathrm{MDP}}$ scintigraphy provides additional helpful findings in the evaluation of children with neuroblastoma. ${ }^{99 \mathrm{~m} T c-M D P}$ is taken up by soft-tissue disease but is predominantly taken up by cortical metastases $(91,93) .{ }^{18}$ F-FDG PET may be used in the evaluation of infants with neuroblastoma. ${ }^{18} \mathrm{~F}-\mathrm{FDG}$ is avidly taken up at sites of disease, and recent reports suggest that ${ }^{18}$ F-FDG PET and ${ }^{123}$ I-MIBG scintigraphy may provide complementary information. ${ }^{123}$ I-MIBG is specific and superior to ${ }^{18} \mathrm{~F}$-FDG PET for the detection of neuroblastoma, but ${ }^{18} \mathrm{~F}$-FDG PET may be helpful in the evaluation of tumors that weakly accumulate ${ }^{123} \mathrm{I}-\mathrm{MIBG}$ (92). The role of ${ }^{18} \mathrm{~F}$-FDG PET or ${ }^{18} \mathrm{~F}$-FDG PET/CT in the evaluation of infants with neuroblastoma has not been established.

Antihypertensive medication, tricyclic antidepressants, and sympathomimetics should be discontinued, if possible, because they interfere with ${ }^{123}$ I-MIBG uptake. A supersaturated solution of potassium iodide should be prescribed to reduce ${ }^{123}$ I uptake by the thyroid gland. Specifically, the infant is given 1 drop of a solution of potassium iodide by mouth 3 times a day starting the day before ${ }^{123}$ I-MIBG injection and continuing for $3 \mathrm{~d}$. If the infant is allergic to iodine, $200 \mathrm{mg}$ of orally administered potassium perchlorate are recommended, starting the day before ${ }^{123}$ I-MIBG injection and continuing for $3 \mathrm{~d}$. The usual dose of ${ }^{123}$ I-MIBG is 37 MBq $(1 \mathrm{mCi}) .{ }^{123} \mathrm{I}-\mathrm{MIBG}$ is administered by slow intrave- nous injection over 2 min. Whole-body planar scintigraphy is normally obtained $24 \mathrm{~h}$ after tracer injection. SPECT of the neck, thorax, abdomen, and pelvis is routinely obtained at our institution. It is estimated that the effective dose for a ${ }^{123} \mathrm{I}$-MIBG scan in a 1 -y-old child is $2.5 \mathrm{mSv}$ (250 mrem) with the above-administered dose (94).

Standard treatment of neuroblastoma may include surgery, chemotherapy, and radiation depending on the stage and biologic factors of the tumor $(88,89)$. ${ }^{131}$ I-MIBG radiotherapy has been used as palliative therapy in children with neuroblastoma.

Other tumors of infancy include Wilms tumors, germ cell tumors, soft-tissue tumors, lymphoma, and hepatic tumors, among others. Wilms tumor (or nephroblastoma) is the most common pediatric renal malignancy (95). The typical clinical presentation for these tumors is an asymptomatic abdominal mass. Anatomic imaging is commonly performed first in the evaluation of these patients. Scintigraphy and PET are infrequently used (89) but may identify sites of disease $(96,97)$. The role of ${ }^{18} \mathrm{~F}-\mathrm{FDG}$ PET in infants with soft-tissue tumors has not yet been established.

\section{ACKNOWLEDGMENTS}

We acknowledge the following individuals: Chris Durall for tireless work on the multiple versions of the manuscript; Nancy Drinan for impeccable editorial work; Michael Stabin for dose estimates; S. James Adelstein for radiation risk estimates; Alan Packard, Pat Gallaher, and Justin Paolino for radiopharmaceutical and contrast agent calculations of volume and mass; Chuck Hornberger for database searches; Joanne Louis, Vicky Kourmouzi, and the technologist staff for their dedication and meticulous technical expertise; and our nurses and child life specialists for their expert care.

\section{REFERENCES}

1. Treves ST. Introduction. In: Treves ST, ed. Pediatric Nuclear Medicine/PET. 3rd ed. New York, NY: Springer; 2007:1-15.

2. Cao X, Tetrault T, Fahey FH, Treves ST. Automated motion correction based on target tracking and software implementation [abstract]. J Nucl Med. 2008;49 (suppl 1):157P.

3. Snay ER, Treves ST, Fahey FH. Improved quality of pediatric ${ }^{123}$ I-MIBG images with medium-energy collimators. J Nucl Med Technol. 2011;39:100-104.

4. Davis RT, Zimmerman RE, Treves ST. Magnification. In: Treves ST, ed. Pediatric Nuclear Medicine/PET. 3rd ed. New York, NY: Springer; 2007:446-456.

5. Treves ST, Davis RT, Fahey FH. Administered radiopharmaceutical doses in children: a survey of 13 pediatric hospitals in North America. J Nucl Med. 2008;49:1024-1027.

6. Lassmann M, Biassoni L, Monsieurs M, Franzius C, Jacobs F. The new EANM paediatric dosage card. Eur J Nucl Med Mol Imaging. 2007;34:796-798.

7. Gelfand MJ, Parisi MT, Treves ST. Pediatric radiopharmaceutical administered doses: 2010 North American consensus guidelines. J Nucl Med. 2011;52:318322 .

8. International Commission on Radiological Protection. ICRP Publication 53: Radiation Dose to the Patient from Radiopharmaceuticals. New York, NY: Pergamon Press; 1988.

9. Stabin M. Internal dosimetry. In: Treves ST, ed. Pediatric Nuclear Medicine/ PET. 3rd ed. New York, NY: Springer; 2007:513-520.

10. Sheehy N, Tetrault TA, Zurakowski D, Vija AH, Fahey FH, Treves ST. Pediatric ${ }^{99 \mathrm{~m}}$ Tc-DMSA SPECT performed by using iterative reconstruction with isotropic 
resolution recovery: improved image quality and reduced radiopharmaceutical activity. Radiology. 2009;251:511-516.

11. Stansfield EC, Sheehy N, Zurakowski D, Vija AH, Fahey FH, Treves ST. Pediatric ${ }^{99 \mathrm{~m}} \mathrm{Tc}-\mathrm{MDP}$ bone SPECT with ordered subset expectation maximization iterative reconstruction with isotropic $3 \mathrm{D}$ resolution recovery. Radiology. 2010;257:793-801.

12. Hsiao E, Cao X, Zukotynski KA, et al. Dose reduction in pediatric MAG-3 renal scans [abstract]. J Nucl Med. 2009;50(suppl 2):253.

13. Romer W, Reichel N, Vija HA, et al. Isotropic reconstruction of SPECT data using OSEM3D: correlation with CT. Acad Radiol. 2006;13:496-502.

14. Vija AH, Yahil A, Hawman EG. Adaptive noise reduction and sharpening of OSEM-reconstructed data. In: IEEE Nuclear Science Symposium Conference Record. October 23-29, 2005:2583-2587.

15. Shi Y, Jin RB, Zhao JN, Tang SF, Li HQ, Li TY. Brain positron emission tomography in preterm and term newborn infants. Early Hum Dev. 2009;85:429-432.

16. Alessio AM, Kinahan PE, Manchanda V, Ghioni V, Aldape L, Parisi MT. Weight-based, low-dose pediatric whole-body PET/CT protocols. J Nucl Med. 2009;50:1570-1577.

17. Kuji I, Sumiya H, Niida Y, et al. Age-related changes in the cerebral distribution of ${ }^{99 m}$ Tc-ECD from infancy to adulthood. J Nucl Med. 1999;40:1818-1823.

18. Chugani HT. Functional brain imaging in pediatrics. Pediatr Clin North Am. 1992;39:777-799.

19. Treves ST, Chugani HC, Bourgeois BF. Central nervous system: part I-brain. In: Treves ST, ed. Pediatric Nuclear Medicine/PET. 3rd ed. New York, NY: Springer; 2007:16-38.

20. Davis RT, Treves ST, Packard AB, Farley JB, Amoling RK, Ulanski JS. Ictal perfusion brain SPECT in pediatric patients with intractable epilepsy: a multidisciplinary approach. J Nucl Med Technol. 1996;24:219-222.

21. Vera P, Kaminska A, Cieuta C, et al. Use of subtraction ictal SPECT co-registered to MRI for optimizing the localization of seizure foci in children. $J$ Nucl Med. 1999;40:786-792.

22. Habboush IH, Mitchell KD, Mulkern RV, Barnes PD, Treves ST. Registration and alignment of three-dimensional images: an interactive visual approach. $R a$ diology. 1996;199:573-578.

23. Treves ST, Kuruc A. Central nervous system: part II-cerebrospinal fluid. In: Treves ST, ed. Pediatric Nuclear Medicine/PET. 3rd ed. New York, NY: Springer; 2007:39-56.

24. Rose SR, Brown RS, Foley T, et al. Update of newborn screening and therapy for congenital hypothyroidism. Pediatrics. 2006;117:2290-2303.

25. LaFranchi S. Congenital hypothyroidism: etiologies, diagnosis, and management. Thyroid. 1999;9:735-740.

26. de Vijlder JJ. Primary congenital hypothyroidism: defects in iodine pathways. Eur J Endocrinol. 2003;149:247-256.

27. Schoen EJ, Clapp W, To TT, Fireman BH. The key role of newborn thyroid scintigraphy with isotopic iodide $\left({ }^{123} \mathrm{I}\right)$ in defining and managing congenital hypothyroidism. Pediatrics. 2004;114:e683-e688.

28. Eugster EA, LeMay D, Zerin JM, Pescovitz OH. Definitive diagnosis in children with congenital hypothyroidism. J Pediatr. 2004;144:643-647.

29. Clerc J, Monpeyssen H, Chevalier A, et al. Scintigraphic imaging of paediatric thyroid dysfunction. Horm Res. 2008;70:1-13.

30. Heyman S, Crigler JF Jr, Treves S. Congenital hypothyroidism: ${ }^{123}$ I thyroidal uptake and scintigraphy. J Pediatr. 1982;101:571-574.

31. Perry RJ, Maroo S, Maclennan AC, Jones JH, Donaldson MD. Combined ultrasound and isotope scanning is more informative in the diagnosis of congenital hypothyroidism than single scanning. Arch Dis Child. 2006;91:972-976.

32. Shapiro B, Britton K, Fountos A, et al. A multiobserver comparison of ${ }^{99} \mathrm{~m}^{\mathrm{TcO}}{ }_{4}$ and ${ }^{123}$ I thyroid imaging. Eur J Nucl Med. 1981;6:135-138.

33. Heyman S. Toxicity and safety factors associated with lung perfusion studies with radiolabeled particles. J Nucl Med. 1979;20:1098-1099.

34. Treves ST, Packard AB. Lungs. In: Treves ST, ed. Pediatric Nuclear Medicine/ PET. 3rd ed. New York, NY: Springer; 2007:87-127.

35. Treves ST, Blume ED, Armsby L, Newburger JW, Kuruc A. Cardiovascular system. In: Treves ST, ed. Pediatric Nuclear Medicine/PET. 3rd ed. New York, NY: Springer; 2007:128-161.

36. Kondo C. Myocardial perfusion imaging in pediatric cardiology. Ann Nucl Med. 2004;18:551-561.

37. Rabinovitch M, Fischer KC, Treves S. Quantitative thallium-201 myocardial imaging in assessing right ventricular pressure in patients with congenital heart defects. Br Heart J. 1981;45:198-205.

38. Maltz DL, Treves S. Quantitative radionuclide angiocardiography: determination of Qp:Qs in children. Circulation. 1973;47:1049-1056.

39. Kuruc A, Treves S, Parker JA, Cheng C, Sawan A. Radionuclide angiocardiography: an improved deconvolution technique for improvement after suboptimal bolus injection. Radiology. 1983;148:233-238.
40. Hurwitz RA, Treves S, Kuruc A. Right ventricular and left ventricular ejection fraction in pediatric patients with normal hearts: first-pass radionuclide angiocardiography. Am Heart J. 1984;107:726-732.

41. Majd M, Reba RC, Altman RP. Effect of phenobarbital on ${ }^{99 m}$ Tc-IDA scintigraphy in the evaluation of neonatal jaundice. Semin Nucl Med. 1981;11:194-204.

42. Gerhold JP, Klingensmith WC III, Kuni CC, et al. Diagnosis of biliary atresia with radionuclide hepatobiliary imaging. Radiology. 1983;146:499-504.

43. Heyman S, Kirkpatrick JA, Winter HS, Treves S. An improved radionuclide method for the diagnosis of gastroesophageal reflux and aspiration in children (milk scan). Radiology. 1979;131:479-482.

44. Lin E, Connolly LP, Drubach L, et al. Effect of early emptying on quantitation and interpretation of liquid gastric emptying studies of infants and young children. J Nucl Med. 2000;41:596-599.

45. Villanueva-Meyer J, Swischuk LE, Cesani F, Ali SA, Briscoe E. Pediatric gastric emptying: value of right lateral and upright positioning. J Nucl Med. 1996;37: 1356-1358.

46. Heyman S, Respondek M. Detection of pulmonary aspiration in children by radionuclide "salivagram." J Nucl Med. 1989;30:697-699.

47. Bar-Sever Z, Connolly LP, Treves ST. The radionuclide salivagram in children with pulmonary disease and a high risk of aspiration. Pediatr Radiol. 1995;25 (suppl 1):S180-S183.

48. Cook SP, Lawless S, Mandell GA, Reilly JS. The use of the salivagram in the evaluation of severe and chronic aspiration. Int J Pediatr Otorhinolaryngol. 1997;41:353-361.

49. Jewett TC Jr, Duszynski DO, Allen JE. The visualization of Meckel's diverticulum with ${ }^{99 m}$ Tc-pertechnetate. Surgery. 1970;68:567-570.

50. Sfakianakis GN, Conway JJ. Detection of ectopic gastric mucosa in Meckel's diverticulum and in other aberrations by scintigraphy: ii. indications and methods-a 10-year experience. J Nucl Med. 1981;22:732-738.

51. Sfakianakis GN, Anderson GF, King DR, Boles ET Jr. The effect of gastrointestinal hormones on the pertechnetate imaging of ectopic gastric mucosa in experimental Meckel's diverticulum. J Nucl Med. 1981;22:678-683.

52. Treves ST, Grand RJ. Gastrointestinal bleeding. In: Treves ST, ed. Pediatric Nuclear Medicine/PET. 3rd ed. New York, NY: Springer; 2007:192-208.

53. Treves ST, Jones AG. Liver and spleen. In: Treves ST, ed. Pediatric Nuclear Medicine/PET. 3rd ed. New York, NY: Springer; 2007:209-238.

54. Treves ST, Harmon W, Packard AB, Kuruc A. Kidneys. In: Treves ST, ed. Pediatric Nuclear Medicine/PET. 3rd ed. New York, NY: Springer; 2007:239-287.

55. Daly MJ, Jones W, Rudd TG, Tremann J. Differential renal function using technetium-99m dimercaptosuccinic acid (DMSA): in vitro correlation. $\mathrm{J} \mathrm{Nucl}$ Med. 1979;20:63-66.

56. Enlander D, Weber PM, dos Remedios LV. Renal cortical imaging in 35 patients: superior quality with ${ }^{99 m}$ Tc-DMSA. J Nucl Med. 1974;15:743-749.

57. Willis KW, Martinez DA, Hedley-Whyte ET, Davis MA, Judy PF, Treves S. Renal localization of ${ }^{99 \mathrm{~m}} \mathrm{Tc}$-stannous glucophetonate and ${ }^{99 \mathrm{~m}} \mathrm{Tc}$-stannous dimercaptosuccinate in the rat by frozen section autoradiography: the efficiency and resolution of technetium-99m. Radiat Res. 1977;69:475-488.

58. Chung YK, Chang PY, Lin CJ, Wang NL, Sheu JC, Shih BF. Conservative treatment of neonatal hydronephrosis. J Formos Med Assoc. 1992;91:75-80.

59. Gordon I, Dhillon HK, Peters AM. Antenatal diagnosis of renal pelvic dilatation: the natural history of conservative management. Pediatr Radiol. 1991;21:272-273.

60. Homsy YL, Saad F, Laberge I, Williot P, Pison C. Transitional hydronephrosis of the newborn and infant. J Urol. 1990;144:579-583.

61. Samuelson U, Granerus G, Bjures J, Hagberg S, Hjalmas K. Renal function in idiopathic hydronephrosis in children: follow-up after conservative and surgical treatment. Scand J Urol Nephrol. 1984;18:135-141.

62. Jakobsson B, Nolstedt L, Svensson L, Soderlundh S, Berg U. ${ }^{99 m}$ Technetiumdimercaptosuccinic acid scan in the diagnosis of acute pyelonephritis in children: relation to clinical and radiological findings. Pediatr Nephrol. 1992;6: 328-334.

63. Majd M, Rushton HG. Renal cortical scintigraphy in the diagnosis of acute pyelonephritis. Semin Nucl Med. 1992;22:98-111.

64. Verber IG, Meller ST. Serial ${ }^{99 \mathrm{~m}}$ Tc dimercaptosuccinic acid (DMSA) scans after urinary infections presenting before the age of 5 years. Arch Dis Child. 1989;64: 1533-1537.

65. Medical versus surgical treatment of primary vesicoureteral reflux: report of the International Reflux Study Committee. Pediatrics. 1981;67:392-400.

66. Normand LCS, Smellie J. Vesicoureteric reflux: the case for conservative management. In: Hodson J, Kincaid-Smith P, eds. Reflux Nephropathy. New York, NY: Masson; 1979: 281-286.

67. Conway JJ, Belman AB, King LR. Direct and indirect radionuclide cystography. Semin Nucl Med. 1974;4:197-211.

68. Treves ST, Willi UV. Vesicoureteral reflux. In: Treves ST, ed. Pediatric Nuclear Medicine/PET. 3rd ed. New York, NY: Springer; 2007:296-306. 
69. Treves ST, Zurakowski D, Bauer SB, Mitchell KD, Nichols DP. Functional bladder capacity measured during radionuclide cystography in children. Radiology. 1996;198:269-272.

70. Ataei N, Madani A, Esfahani ST, et al. Screening for vesicoureteral reflux and renal scars in siblings of children with known reflux. Pediatr Nephrol. 2004;19: 1127-1131.

71. Connolly LP, Treves ST, Zurakowski D, Bauer SB. Natural history of vesicoureteral reflux in siblings. J Urol. 1996;156:1805-1807.

72. Noe HN. The long-term results of prospective sibling reflux screening. J Urol. 1992;148:1739-1742.

73. Van den Abbeele AD, Treves ST, Lebowitz RL, et al. Vesicoureteral reflux in asymptomatic siblings of patients with known reflux: radionuclide cystography. Pediatrics. 1987;79:147-153.

74. Kenda RB, Fettich JJ. Vesicoureteric reflux and renal scars in asymptomatic siblings of children with reflux. Arch Dis Child. 1992;67:506-508.

75. Buonomo C, Treves ST, Jones B, Summerville D, Bauer S, Retik A. Silent renal damage in symptom-free siblings of children with vesicoureteral reflux: assessment with technetium Tc 99m dimercaptosuccinic acid scintigraphy. J Pediatr. 1993;122:721-723.

76. Connolly LP, Drubach LA, Connolly SA, Treves ST. Bone. In: Treves ST, ed. Pediatric Nuclear Medicine/PET. 3rd ed. New York, NY: Springer; 2007:312-403.

77. Grant FD, Fahey FH, Packard AB, Davis RT, Alavi A, Treves ST. Skeletal PET with ${ }^{18}$ F-fluoride: applying new technology to an old tracer. J Nucl Med. 2008;49:68-78.

78. ACR Practice Guideline for Skeletal Surveys in Children. Reston, VA: American College of Radiology; 2006:1-5.

79. Bressler EL, Conway JJ, Weiss SC. Neonatal osteomyelitis examined by bone scintigraphy. Radiology. 1984;152:685-688.

80. Harcke HT Jr. Bone imaging in infants and children: a review. J Nucl Med. 1978;19:324-329.

81. Heinrich SD, Gallagher D, Harris M, Nadell JM. Undiagnosed fractures in severely injured children and young adults: identification with technetium imaging. J Bone Joint Surg Am. 1994;76:561-572.

82. Kemp AM, Butler A, Morris S, et al. Which radiological investigations should be performed to identify fractures in suspected child abuse? Clin Radiol. 2006;61: $723-736$.
83. Mandelstam SA, Cook D, Fitzgerald M, Ditchfield MR. Complementary use of radiological skeletal survey and bone scintigraphy in detection of bony injuries in suspected child abuse. Arch Dis Child. 2003;88:387-390.

84. Nadel HR. Pediatric bone scintigraphy update. Semin Nucl Med. 2010;40:31-40.

85. Drubach LA, Johnston PR, Newton AW, Perez-Rossello JM, Grant FD, Kleinman PK. Skeletal trauma in child abuse: detection with ${ }^{18} \mathrm{~F}-\mathrm{NaF}$ PET. Radiology. 2010;255:173-181.

86. Gurney JG, Smith MA, Ross JA. Cancer among infants. National Cancer Institute SEER Pediatric Monograph. 1975-1995. Available at: http://seer.cancer.gov/ publications/childhood/infant.pdf. Accessed April 14, 2011.

87. United States Cancer Statistics: 1999-2007 Cancer Incidence and Mortality Data. National Program of Cancer Registries Web site. Available at: http:// apps.nccd.cdc.gov/uscs/. Accessed April 14, 2011

88. Lonergan GJ, Schwab CM, Suarez ES, Carlson CL. Neuroblastoma, ganglioneuroblastoma, and ganglioneuroma: radiologic-pathologic correlation. Radiographics. 2002;22:911-934.

89. Jadvar H, Shulkin BL. Pediatric oncology. In: Treves ST, ed. Pediatric Nuclear Medicine/PET. 3rd ed. New York, NY: Springer; 2007:404-418.

90. Hattner RS, Huberty JP, Engelstad BL, Gooding CA, Ablin AR. Localization of m-iodo $\left({ }^{131} \mathrm{I}\right)$ benzylguanidine in neuroblastoma. AJR. 1984;143:373-374.

91. Shulkin BL, Shapiro B, Hutchinson RJ. Iodine-131-metaiodobenzylguanidine and bone scintigraphy for the detection of neuroblastoma. J Nucl Med. 1992;33: 1735-1740.

92. Sharp SE, Shulkin BL, Gelfand MJ, Salisbury S, Furman WL. ${ }^{123}$ I-MIBG scintigraphy and ${ }^{18}$ F-FDG PET in neuroblastoma. J Nucl Med. 2009;50:1237-1243.

93. Perel Y, Conway J, Kletzel M, et al. Clinical impact and prognostic value of metaiodobenzylguanidine imaging in children with metastatic neuroblastoma. J Pediatr Hematol Oncol. 1999;21:13-18.

94. International Commission on Radiological Protection. ICRP Publication 80: Radiation Dose to Patients from Radiopharmaceuticals. New York, NY: Pergamon Press; 2000.

95. McHugh K. Renal and adrenal tumours in children. Cancer Imaging. 2007;7: 41-51.

96. Murphy JJ, Tawfeeq M, Chang B, Nadel H. Early experience with PET/CT scan in the evaluation of pediatric abdominal neoplasms. J Pediatr Surg. 2008;43:2186-2192.

97. Shulkin BL, Chang E, Strouse PJ, Bloom DA, Hutchinson RJ. PET FDG studies of Wilms tumors. J Pediatr Hematol Oncol. 1997;19:334-338. 